\title{
Computing a Large Refined Catalog of Focal Mechanisms for Southern California (1981-2010): Temporal Stability of the Style of Faulting
}

\author{
by Wenzheng Yang, Egill Hauksson, and Peter M. Shearer
}

\begin{abstract}
Using the method developed by Hardebeck and Shearer (2002, 2003) termed the HASH method, we calculate focal mechanisms for earthquakes that occurred in the southern California region from 1981 to 2010. When available, we use hypocenters refined with differential travel times from waveform cross correlation. Using both the $P$-wave first motion polarities and the $S / P$ amplitude ratios computed from three-component seismograms, we determine mechanisms for more than 480,000 earthquakes and analyze the statistical features of the whole catalog. We filter the preliminary catalog with criteria associated with mean nodal plane uncertainty and azimuthal gap and obtain a high-quality catalog with approximately 179,000 focal mechanisms. As more $S / P$ amplitude ratios become available after 2000 , the average nodal plane uncertainty decreases significantly compared with mechanisms that include only $P$-wave polarities. In general the parameters of the focal mechanisms have been stable during the three decades. The dominant style of faulting is high angle strike-slip faulting with the most likely $P$ axis centered at $\mathrm{N} 5^{\circ} \mathrm{E}$. For earthquakes of $M<2.5$, there are more normal-faulting events than reverse-faulting events, while the opposite holds for $M>2.5$ events. Using the 210 moment-tensor solutions in Tape et al. (2010) as benchmarks, we compare the focal plane rotation angles of common events in the catalog. Seventy percent of common earthquakes match well with rotation angles less than the typical nodal plane uncertainty. The common events with relatively large rotation angles are either located around the edge of the (SCSN) network or poorly recorded.
\end{abstract}

Online Material: Table of HASH parameter settings and figures of 1D velocity models, distribution of earthquakes with different focal-mechanism qualities, comparison of YHS2010 and HS2003 catalogs, and distributions of earthquake focal mechanisms.

\section{Introduction}

While the hypocenter of an earthquake reveals the location of the causative fault, the focal mechanism is a description of the style of faulting or the possible fault orientations and sense of motion. A catalog of regional earthquake focal mechanisms can be used to improve understanding of the contemporary seismotectonic processes and can contribute to an evaluation of potential seismic hazard. Furthermore, the temporal and spatial variations of regional stress field orientation could be determined by inverting a diverse set of focal mechanisms.

Moment-tensor inversion methods that are based on fitting recorded and synthetic waveforms have been used to calculate focal mechanisms for earthquakes in the southern California region (e.g., Liu et al., 2004; Clinton et al., 2006; Tape et al., 2010; Lee et al., 2011). Other waveform fitting methods such as the cut-and-paste (CAP) method (Zhao and Helmberger, 1994; Zhu and Helmberger, 1996; Tan and Helmberger, 2007) were developed to calculate focal mechanisms of earthquakes with $M \geq 2.5$ in southern California. The dependency on waveform fitting that often needs to be reviewed by a seismologist limits the application of such methods to moderate to large earthquakes with highquality waveforms.

Small earthquakes $(0<M<4)$ make up the bulk of the regional earthquake data set. We approximate them as point sources because the associated source sizes (rupture area $<1 \mathrm{~km}^{2}$ (e.g., Kanamori and Anderson, 1975; Wells and Coppersmith, 1994) are far smaller than the average epicentral distance. Commonly, focal mechanisms for small earthquakes have been calculated using the $P$-wave first motion 
polarities (hereafter shortened to polarities) with programs such as FPFIT (Reasenberg and Oppenheimer, 1985) in many different studies (e.g., Jones, 1988; Wang et al., 1995; Sue et al., 1999). As an improvement to the FPFIT method, which only considers the possible uncertainty associated with polarities, the method developed by Hardebeck and Shearer (2002, 2003; HASH) takes into account additional uncertainties such as earthquake location error and variations of velocity models. Previous comparisons (Hardebeck and Shearer, 2002; Kilb and Hardebeck, 2006) showed that the HASH method provides focal mechanisms that are more consistent with seismicity trends.

Among all the source signals preserved in a seismic waveform, the $S / P$ amplitude ratio (hereafter shortened to $S / P$ ratio) is the strongest signal relative to other phases. The $S / P$ ratio is generally independent of path effects, site effects, or instrumental response. To the first order, it is also directly proportional to the seismic energy radiation pattern as measured on the source focal sphere. Hardebeck and Shearer (2003) showed that the observed $S / P$ ratios are generally consistent with the expected focal mechanisms, and they also showed that $S / P$ ratios could be used to estimate focal mechanisms of small and large earthquakes. On the focal sphere, the $S / P$ ratio reaches its peak value near the nodal planes, where the signal of polarities become very small. While the $S / P$ ratio reaches the smallest value near the $P$ or $T$ axis, the signal of polarities can be large. Thus, the $S / P$ ratios provide important additional information to constrain the focal mechanism besides polarities. Therefore, computing focal mechanisms by using both polarities and $S / P$ ratios provides more accurate and robust earthquake focal mechanisms than only using polarities.

As part of the upgrade of the Southern California Seismic Network (SCSN) during the last decade, the single-component short-period vertical seismometers (e.g., EHZ) have been replaced with broadband three-component seismometers (e.g., HHE, HHN, HHZ). Because threecomponent earthquake waveforms are now available routinely, it has become possible to calculate focal mechanisms for both large and small earthquakes at a high level of accuracy by using both polarities and $S / P$ ratios.

In this paper, we describe how the new catalog of focal mechanisms for southern California was determined. We also discuss how the quality of the polarities and $S / P$ ratios has changed with time and its effects on the accuracy of the focal mechanisms. We also provide analysis of this new catalog to determine average styles of faulting in the southern California region over the past 30 years and associated temporal variations.

\section{SCSN Data}

We processed earthquake data recorded by the SCSN from 1981 to 2010. During this period, the SCSN had undergone a steady upgrade from short-period single component seismometers to three-component broadband seismometers, with a total of 160 broadband stations and 132 short-period stations by the end of 2008 (Hutton et al., 2010). The stations are unevenly distributed, with more stations located around the greater Los Angeles metropolitan area, compared to the remote areas of eastern California (Fig. 1). More than 483,000 local earthquakes were recorded by the SCSN from 1 January 1981 to 12 December 2010, with magnitudes ranging between -0.3 and 7.3. The number of earthquakes recorded by the SCSN is on average more than 1000 per month, but the number peaks during large aftershock sequences following major regional earthquakes (e.g., the $1992 M_{\mathrm{w}} 7.2$ Landers earthquake, the $2010 M_{\mathrm{w}} 7.2 \mathrm{El}$ Mayor-Cucapah earthquake). There are no available monthly data for March 1981 because the waveforms could not be archived (Hutton et al., 2010).

\section{Data Processing}

In this study, we used a relocated catalog that was obtained by applying waveform cross-correlation techniques and a double-difference approach for seismicity in the southern California region (E. Hauksson, manuscript in prep., 2012), and the location methods are similar to those that were applied by Lin et al. (2007).

\section{Polarities and $S / P$ Ratios}

We used polarities that were picked and reviewed by data analysts of the SCSN and archived at the Southern California Earthquake Data Center (SCEDC; Hutton et al., 2010). For stations with reverse polarities, we documented the reverse periods using teleseismic earthquakes and corrected the polarities before calculation. The percentage of random pick error in the polarities is generally less than $5 \%$.

To calculate $P$ - and $S$-wave amplitudes, we used waveforms recorded with three-component sensors with the Standard for the Exchange of Earthquake Data (SEED) channel names of (HHE, HHN, HHZ, BHE, BHN, BHZ, HNE, $\mathrm{HNN}$, or HNZ). We standardized the sampling rates of the employed waveforms to $100 \mathrm{~Hz}$, and filtered the waveforms in a $1-10 \mathrm{~Hz}$ frequency range, which is consistent with other studies (e.g., Shearer, 1997).

Figure 2 illustrates the selection of background noise and $P$ and $S$ signal windows for the three-component waveforms for one earthquake. We used $P$ and $S$ arrival times to select signal windows for the measurements of amplitude. We also used associated analyst-picked $P$ and $S$ arrivals that were available, or we estimated the arrivals from the event origin time and the hypocenter station locations with the 1D velocity model for southern California (Hutton et al., 2010). We selected waveform segments inside a -0.5 to $1.5 \mathrm{~s}$ range relative to the $P$ and $S$ arrivals to be the $P$ and $S$ signal windows, respectively. We also selected waveform segments inside a -2.5 to -0.5 s range related to the $P$ arrival to be the background noise window. In each signal window, we took the difference between the maximum and the minimum 


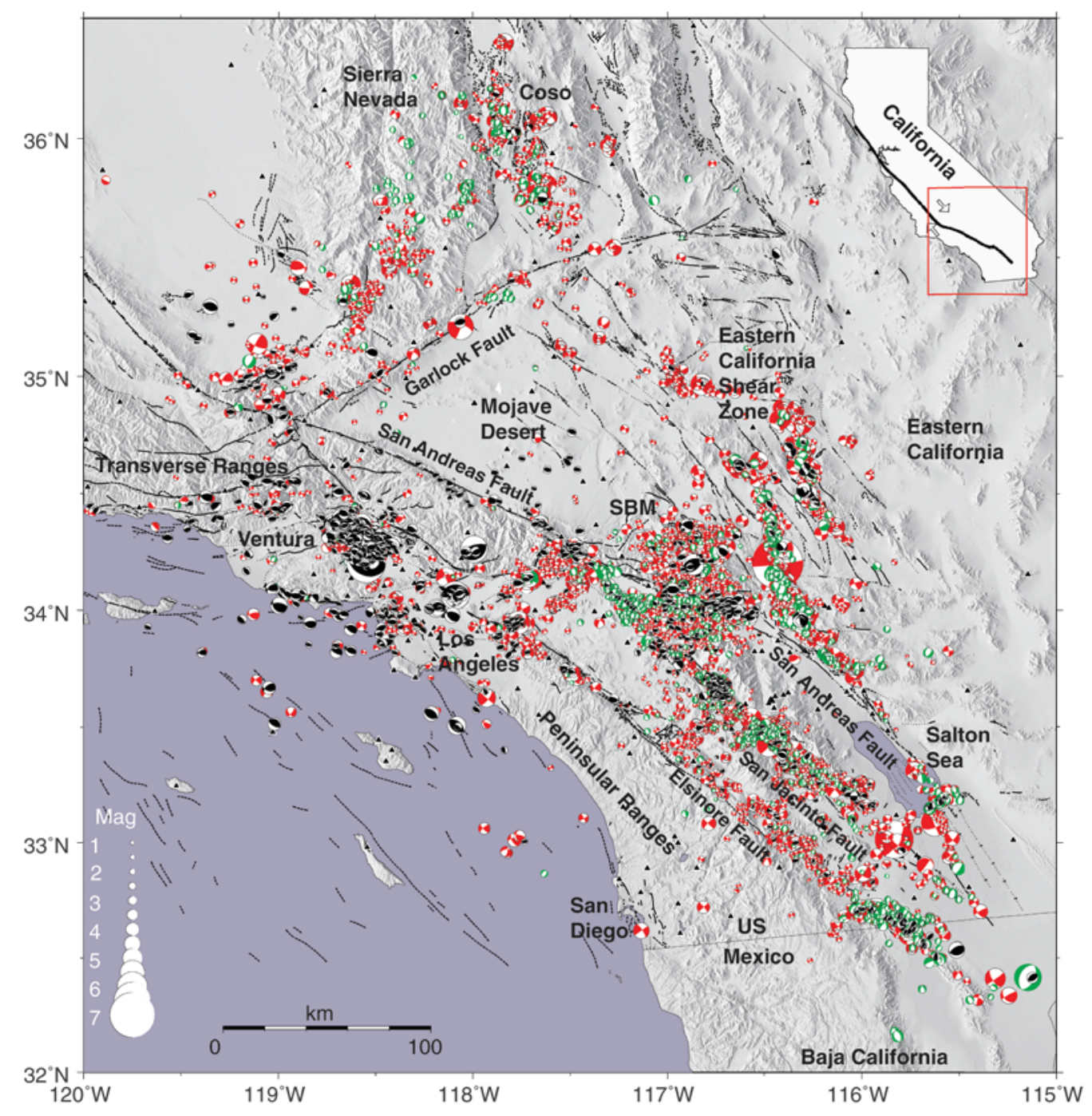

Figure 1. Map view of quality A focal mechanisms for about 13,000 earthquakes from the refined $P$-wave first motion polarities and $S / P$ ratio focal-mechanism catalog (1981-2010). Focal mechanisms are plotted in the order of strike-slip (red), normal (green), and reverse (black). For each style of faulting, events are overlapped in temporal order. The size of each beach ball is scaled with magnitude shown in legend at the bottom left corner. Seismic stations are shown as triangles. Late Quaternary faults are plotted as black curves. SBM indicates the San Bernardino Mountains. The inset panel at the top right shows the relative location of the map area (red box) in California. The San Andreas fault, shown as a bold black curved line in the inset panel, separates the Pacific plate and the North America plate, and arrows indicate relative plate motion.

amplitude values to be the signal amplitude, and applied vector summation over three components to obtain the noise and $P$ - and $S$-wave amplitudes. We then calculated $S / P$ ratios for all available waveforms. If the time interval between $P$ and $S$ arrivals is less than $2.0 \mathrm{~s}$, we did not use the $S / P$ ratio from the associated station.

There are also other possible measurement choices of $P$ - and $S$-wave windows, but the $S / P$ ratio is not significantly sensitive to the different selections, as discussed in Hardebeck and Shearer (2003). The signal window selection approach described previously is one of the simplest and the most robust measurement choices (Hardebeck and Shearer, 2003).

The available polarities and $S / P$ ratios from the SCSN for around 481,000 earthquakes from 1981 to 2010 are shown in Figure 3. With the progressive improvement of the SCSN network, station density has been increasing gradually, and the number of polarities per event has remained stable with a mean value of nine per event. In comparison, the mean number of $S / P$ ratios per event increased in two steps: (1) increasing from zero in the 1980s to around 0.43 in the 1990s because of the first introduction of three-component broadband digital seismometers of the TERRAscope project in 1987 (Kanamori et al., 1993); and (2) increasing to an average of 6.4 per event since 2003 because of a major upgrade to the SCSN during 1997-2002, when most single-component seismometers were replaced with three-component seismometers (Hauksson et al., 2001; Hutton et al., 2010).

\section{Selection Criteria for Focal-Mechanism Calculations}

Similar to Hardebeck and Shearer (2003), we required at least $8 P$ polarities (npolmin) per event, and the minimum 


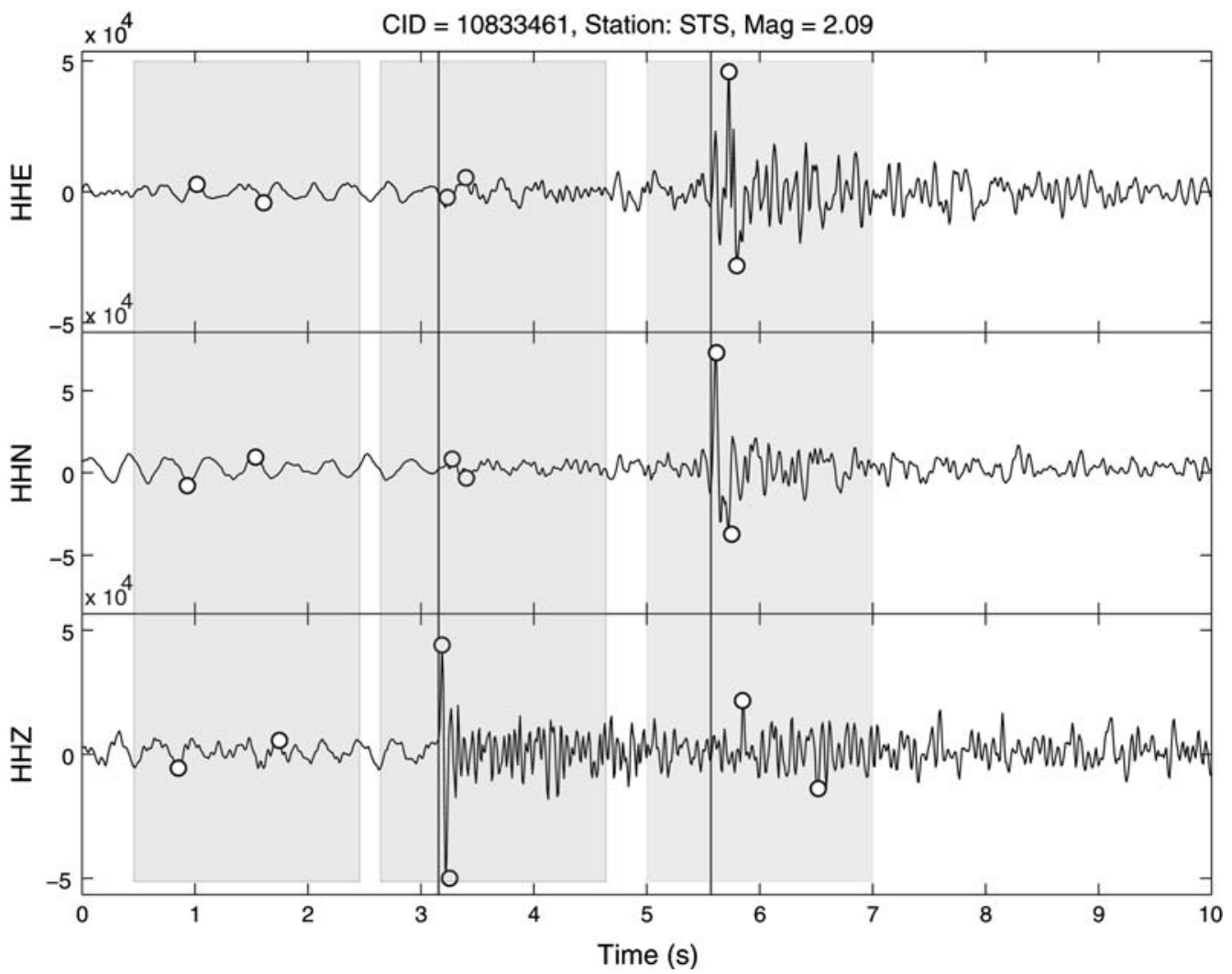

Figure 2. The windows for measuring peak-to-peak pre-event noise, and $P$ - and $S$-wave amplitudes from three-component waveforms. The waveforms are from an event $(\mathrm{CID}=10833461)$ with $M_{\mathrm{L}} 2.09$ and recorded at station STS. The two vertical lines mark the arrival times of the $P(\sim 3.2 \mathrm{~s})$ and $S(\sim 5.6 \mathrm{~s})$ waves. The three consecutive shadows mark the 2 -s signal window for pre-event noise, $P$ wave, and $S$ wave, respectively. In each phase window, the open dots mark the maximum and minimum amplitudes.

$P$-to-noise amplitude ratio (ratmin) to be 3.0. For the azimuthal gap and takeoff gap parameters, we applied the least restrictive requirements to obtain focal-mechanism solutions for the maximum number of events for the purpose of filtering parameter selection in the next step. We set the maximum azimuthal gap (max_agap) to be $360^{\circ}$, and the maximum takeoff angle gap (max_pgap) to be $90^{\circ}$. To minimize computational time, we select a grid angle for focalmechanism search (dang) of $5^{\circ}$ and calculate 30 trial (nmc) solutions. In each trial, the original earthquake depth is perturbed by the associated absolute depth uncertainty given in the catalog multiplied by a Gaussian random variable. If there is no depth uncertainty record in the catalog, the HASH program assigns the depth error to be $0.6 \mathrm{~km}$. Taking into account the observed polarity error in the SCSN data set, we set the fraction of bad polarities (badfrac) to be $5 \%$. In agreement with Hardebeck and Shearer (2003), who showed that the $S / P$ ratio scatter is typically a factor of 2.0 for data in southern California, we select the acceptable variation of the $S / P$ ratio (qbadfrac) to be 0.3 in $\log _{10}$ scale. We set the maximum allowed epicentral distance (delmax) to be $120 \mathrm{~km}$, and the angle for computing the mechanism probability (cangle) to be $45^{\circ}$. Although we set the probability threshold for multiples (prob_max) to be 0.1, we only keep the best solution for simplicity. (E)Table S1 (available as an electronic supplement to this paper) lists the input parameters for the HASH program, and (E)Figure S1 (see the electronic supplement) shows the employed nine 1D velocity models

(a)

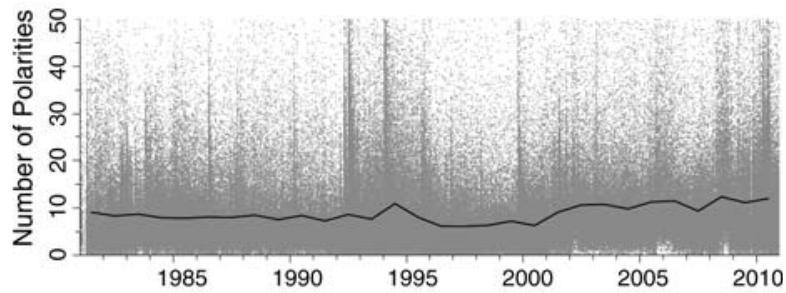

(b)

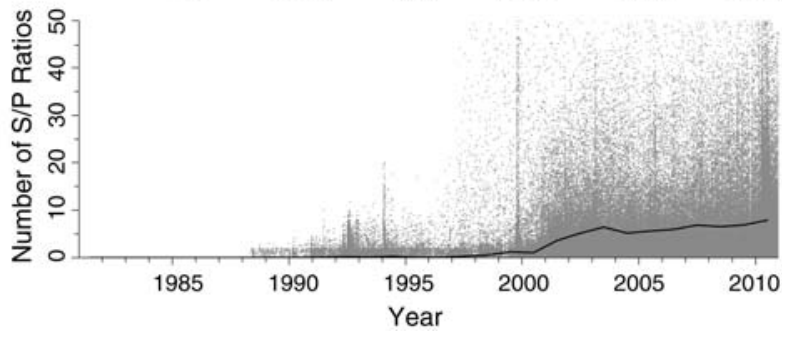

Figure 3. (a) The number of polarities (gray dots) per event and (b) the number of $S / P$ ratios (gray dots) per event for all earthquakes recorded by the SCSN from 1981 through 2010. For visualization, the numbers of observations are perturbed with random noise in the -1.0 to 1.0 range. In each subplot, the dark curve marks the average values of numbers per year over the three decades. 
for the southern California region that account for regional variations in the velocity structure (Shearer, 1997; Hauksson, 2000).

The solutions that have fitting errors less than the selected cutoff value are called acceptable solutions. The preferred solution is the most probable solution, given the distribution of acceptable mechanisms (Hardebeck and Shearer, 2002). The acceptable nodal planes are the planes associated with the acceptable solutions. Similarly, the preferred planes are the nodal planes associated with the preferred solution that is listed in the catalog.

\section{Station Corrections}

At shallow depth, $S$ waves usually suffer more attenuation than $P$ waves, and the observed $S / P$ ratios are generally less than the theoretical predicted values. Previous studies (Shen et al., 1997; Hardebeck and Shearer, 2003) suggested the removal of the station correction, which is the bias between the histogram of recorded $S / P$ ratios at each station and a histogram of randomly sampled theoretical $S / P$ ratios. However, we observe only a systematic bias of $S / P$ ratios that has little or no effect on the obtained focal mechanisms, which rely on the relative variation in $S / P$ ratios.

We computed the distributions of $\log _{10} S / P$ ratios from 2000 to 2010 for all three-component stations, and all distributions generally follow the Gaussian distribution. Figure 4a shows the distribution of the mean values of station $\log _{10} S / P$ ratios and the mean value of theoretical $\log _{10} S / P$ ratios, which were calculated from 280,000 random samplings on the focal sphere (J. Hardebeck, personal comm., 2010). The mean values of station $\log _{10} S / P$ ratios are mostly in the range of $0.0-0.7$, with a mode value of 0.44 . The observed $\log _{10} S / P$ ratio distributions among all stations have a smaller mean value than the mean value of theoretical $\log _{10}$ $S / P$ ratio distribution $(=1.0)$. For most stations, the associated station corrections are at the same level, with values close to -0.56 . As a result of such systematic bias, the obtained focal-mechanism solution will not be affected by whether we take into account the station corrections or not, because the fitting of $S / P$ ratios depends on the relative differences in $S / P$ ratios among stations rather than the absolute values.

Using recent earthquake clusters identified from waveform cross correlation (E. Hauksson, manuscript in prep., 2012) with enough $S / P$ ratios, we tested the effects of including station corrections in determining the focal mechanism. For a test, we used 38 earthquakes that occurred after 2005 and belong to a spatially tight cluster in the San Bernardino region. We calculated focal mechanisms of these events using two different approaches with the HASH method: (1) using polarities and $S / P$ ratios without station corrections and; (2) using polarities and $S / P$ ratios with station corrections. Figure $4 \mathrm{~b}$ shows the results for one event with both approaches and associated $S / P$ ratio variations in log scale. When including the station corrections, the corrected $S / P$ (a)

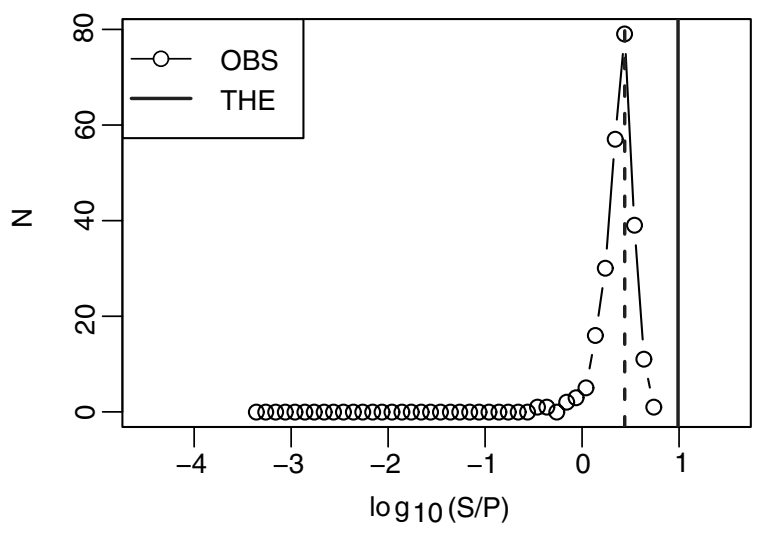

(b)

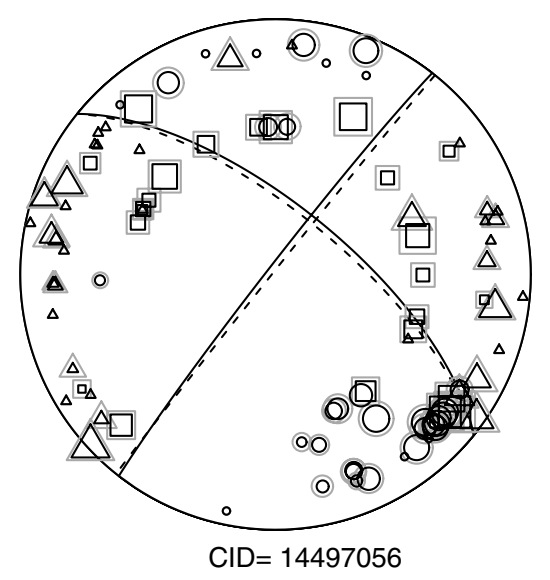

(c)

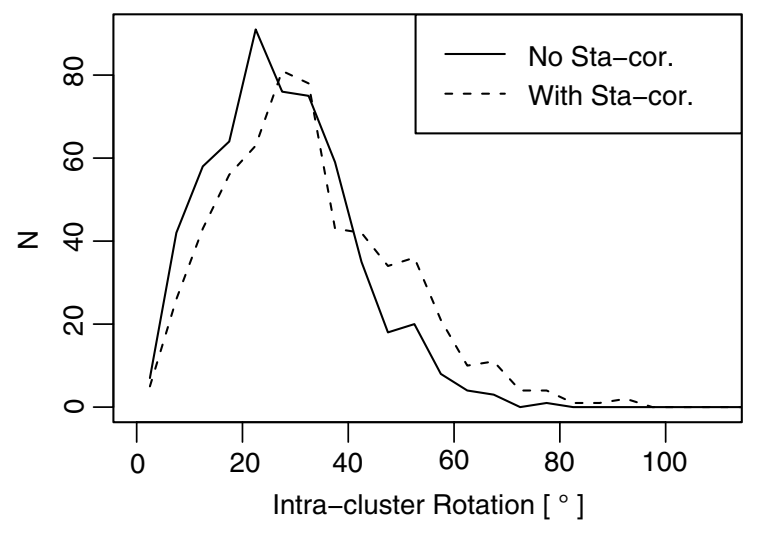

Figure 4. Comparisons and data for mechanisms determined with or without station corrections. (a) The distribution of mean values of $\log _{10} S / P$ ratios for three-component stations of the SCSN in the $2000 \mathrm{~s}$ (OBS, line with open dots) and the peak value at 0.44 is marked by the dashed line. The mean value of theoretical $\log _{10} S / P$ ratios at 1.0 is marked by the solid line (THE). (b) A comparison of calculated nodal planes and associated $S / P$ ratios on the focal sphere for one sample earthquake (event ID 14497056). $S / P$ ratios with and without station corrections are in gray and black, respectively. The triangles indicate up polarities, the circles are for down polarities, and the squares indicate that polarity information is not available. The small size symbols indicate stations with polarities and without $S / P$ ratios. Nodal planes fitted with and without station corrections are shown as dashed and solid curves, respectively. (c) Histograms of intra-cluster rotation angles among the 38 focal mechanisms of a cluster that were calculated with and without using station corrections. 
ratios for all stations are generally equally enlarged in scale. For each set of focal mechanisms, we calculated the intrarotation angles among all earthquake pairs $(N=703)$. The rotation angle is defined as the minimum rotation about any axis that is needed to make two focal mechanisms identical (Hardebeck and Shearer, 2002) and has the range of $0^{\circ}-120^{\circ}$ (Kagan, 1991). For a given set of $N$ events, the intra-rotation angle is the rotation angle between any two events in the set. The histograms of intra-cluster rotation angles (Fig. 4c) show that results from both approaches share nearly the same distribution, but the approach with no station corrections has relatively smaller variation and a smaller mode value. Therefore, we did not take station corrections into account to determine the final catalog of focal mechanisms.

When both polarities and $S / P$ ratios are used, the uncertainty associated with focal-mechanism solutions is smaller than the uncertainty associated with solutions obtained from the fitting of polarities only. In Figure 5 we compare the focal mechanism for one recent 2009 event $\left(M_{\mathrm{L}} 1.8\right)$ calculated with the HASH program using only polarities with the focal mechanism calculated using both polarities and $S / P$ ratios. Clearly, by including the $S / P$ ratios, the number of acceptable focal-mechanism solutions decreases, because more data constraints are required. In addition, the uncertainty of the determined nodal planes drops considerably as the distribution of acceptable solutions becomes more focused around the preferred solution.

\section{Results}

We calculated a preliminary catalog of 202,259 focal mechanisms, each with strike, dip, and rake for one of the two nodal planes of each mechanism, and associated uncertainties by removing most of the constraints in the HASH method. The uncertainty of each nodal plane is defined as the root-mean-square (RMS) angular difference of the acceptable nodal planes from the preferred planes after removing outliers, as described by Hardebeck and Shearer (2002). Both of the nodal plane uncertainties are statistically identical. First, we characterized the preliminary catalog as a whole and analyzed the nodal plane uncertainties to determine optimal filtering parameters. Second, we applied these filtering parameters to obtain a catalog of reliable mechanisms.

\section{Nodal Plane Uncertainties}

Using the preliminary catalog, we determined the relationships between nodal plane uncertainties and 12 different parameters shown in Figure 6. The mechanism probability is defined as the fraction of the acceptable solutions that exist within cangle $\left(45^{\circ}\right.$ in this study) of the preferred solutions. As shown in Figure 6a, the mechanism probability is inversely related to the nodal plane uncertainty. For events with a mechanism probability of 1.0 , the smallest nodal plane uncertainty is around $10^{\circ}$. The value of nodal plane uncertainty is always larger than $0^{\circ}$, because it depends on the grid search angle, the acceptable uncertainty of polarities and $S / P$ ratios, the location errors, and the variation of the velocity models used in the HASH program. The station distribution ratio (STDR) represents the distribution of observations on the focal sphere (Reasenberg and Oppenheimer, 1985). If the STDR is small, most of the observations are close to the nodal planes. The fraction of polarity misfit also contributes to the mechanism uncertainty, where 0.0 is a perfect fit and 1.0 would be a perfect misfit. Although STDR and polarity misfit are often used to classify mechanisms, there are no obvious trends of clusters in STDR (Fig. 6b) or polarity misfit (Fig. 6c) that allow simple A, B, C, etc., quality type classification of the mechanisms.

The nodal plane uncertainty is inversely related to the number of polarities (Fig. 6d) or $S / P$ ratios (Fig. 6g) as expected. The azimuthal gap represents the maximum angular distance between two neighboring stations on the focal sphere. The nodal plane uncertainty generally follows a positive trend with increasing azimuthal gap (Fig. 6e), with a change from positive slope to horizontal slope around $90^{\circ}$. The takeoff gap is the maximum takeoff angular distance between two neighboring stations. Figure $6 \mathrm{f}$ shows that the variations in takeoff gaps are not diagnostic for mechanism quality because of the lack of obvious trends of the density contour shapes along the takeoff gap.

Similarly, the nodal plane uncertainty does not vary significantly with magnitude (Fig. 6h), depth (Fig. 6i), strike (Fig. 6j), rake (Fig. 6k), or dip (Fig. 61). We also compared the relationship between nodal plane uncertainties and obtained focal parameters (Fig. 6j-1). The relationship between nodal plane uncertainty and strike follows a $180^{\circ}$ circular symmetric bimodal distribution. To catch the distribution property of strikes in one $180^{\circ}$ range, we overlapped the strikes in the range between $70^{\circ}$ and $250^{\circ}$ (Fig. 6j). Similarly, we took the absolute value of rake in Figure $6 \mathrm{k}$. The nodal plane uncertainties are generally unrelated to the focal parameters. The HASH program also provides $S / P$ ratio misfit with a round value in $\log _{10}$ scale, but there is no obvious trend between $S / P$ ratio misfits and focal plane uncertainties.

To analyze the temporal variation of nodal plane uncertainties and the improvement of using both polarity and $S / P$ ratios, we also calculated focal-mechanism solutions for the same data set using only polarities (Fig. 7). As discussed in Polarities and $S / P$ Ratios, the $S / P$ ratios became abundant after 2000 following a major SCSN instrument upgrade. Consequently, the average nodal plane uncertainties obtained by including both polarities and $S / P$ ratios have dropped significantly from $45^{\circ}$ in 2000 to $36^{\circ}$ in 2010 . As a comparison, the annual nodal plane uncertainties obtained by only using polarities varied in the range of $40^{\circ}$ to $45^{\circ}$ over the three decades.

\section{Refined Catalog}

To determine a refined catalog with high-quality focal mechanisms, we used selection criteria based on parameters 
(a)

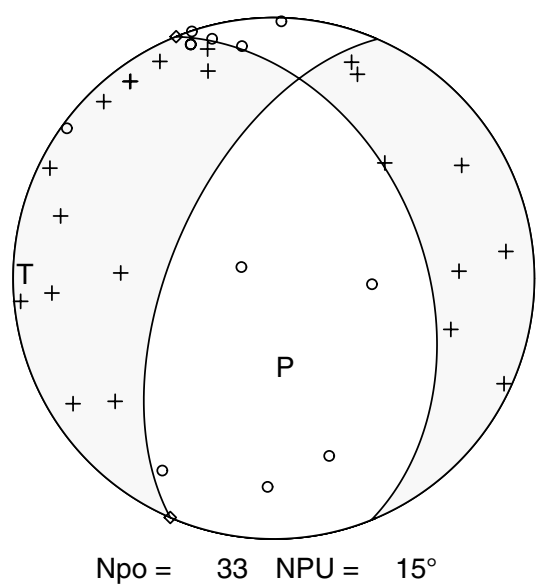

(c)

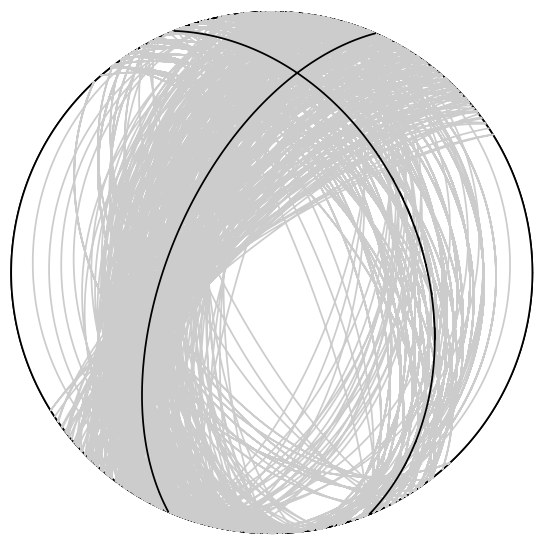

(e)

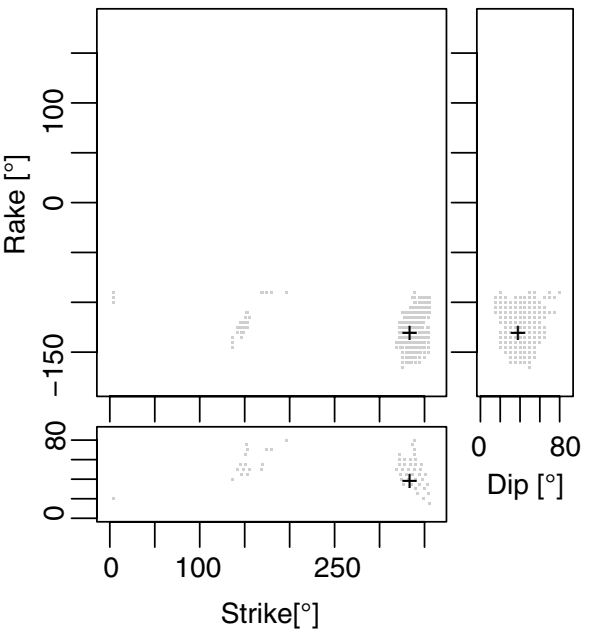

(b)

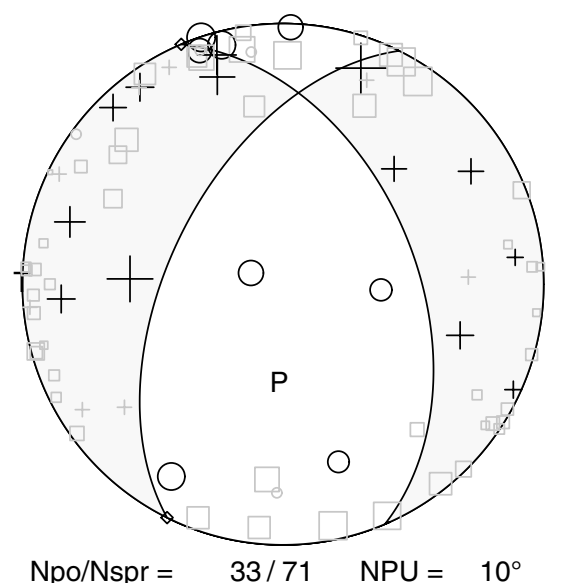

(d)

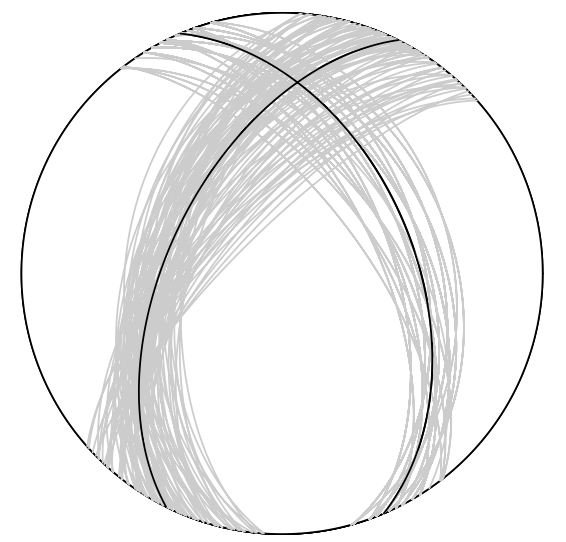

(f)

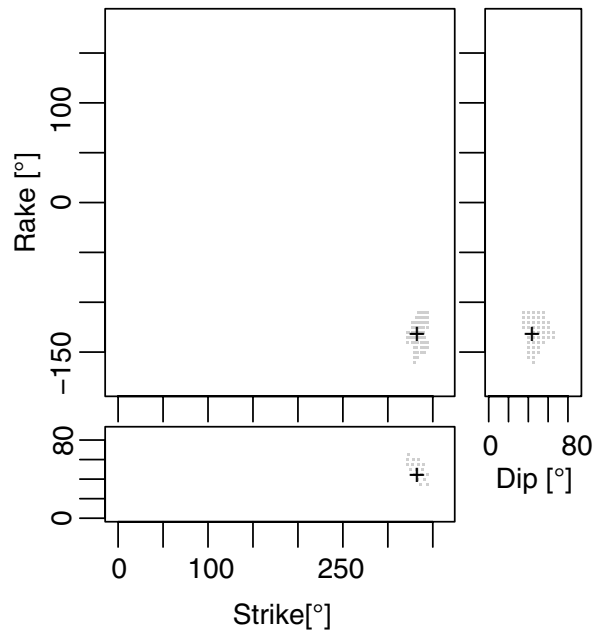

Figure 5. (a) Focal mechanisms for an $M_{\mathrm{L}} 1.81$ earthquake determined with the HASH method by using polarities only, and (b) using both polarities and $S / P$ ratios. Stations are projected onto the stereonet, with $P$-wave polarities (the + symbols indicate up, and the o symbols indicate down). Stations with an $S / P$ ratio and without polarity are shown as open-squares, and stations with polarity and without an $S / P$ ratio are indicated with small gray symbols. For stations with $S / P$ ratios, the symbols are scaled with $\log _{10} S / P$ ratios. $P$ and $T$ axes are also shown. The number of polarities (Npo), $S / P$ ratios (Nspr), and the nodal plane uncertainty (NPU) are labeled at the bottom. (c, d) The distribution of acceptable focal-mechanism solutions (gray curves) and the preferential solution (black curves) are shown on the stereonets for (a) and (b), respectively. (e, f) The distribution of acceptable solutions (gray dots) and the preferential solution (bold crosses) in focal parameter spaces are shown for (a) and (b), respectively.

that are sensitive to the variation of data quality and the data coverage on the focal sphere. We did not use the number of available $S / P$ ratios to determine the focal-mechanism quality because their availability varies with time. Nodal plane uncertainty is correlated with the number of observations in which the more observations the smaller the range of uncertainty. Kilb and Hardebeck (2006) showed that the best single parameter indicator of mechanism quality is the mean 
(a)

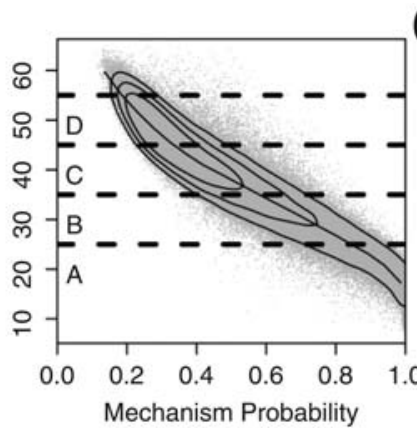

(b)

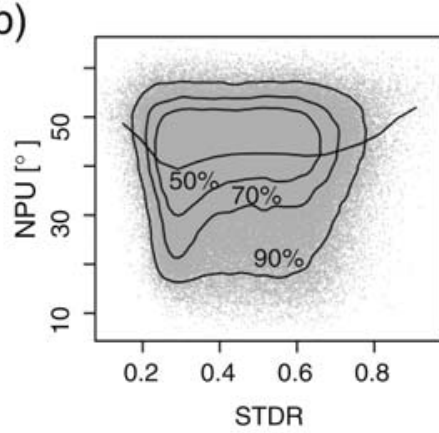

(c)

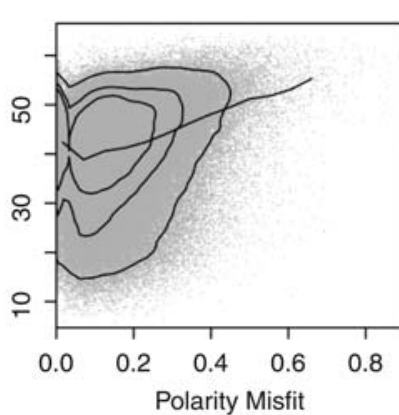

(d)

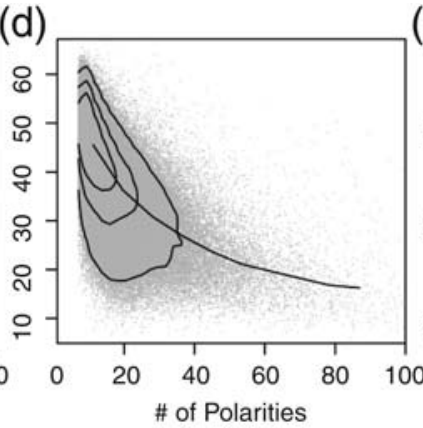

(g)

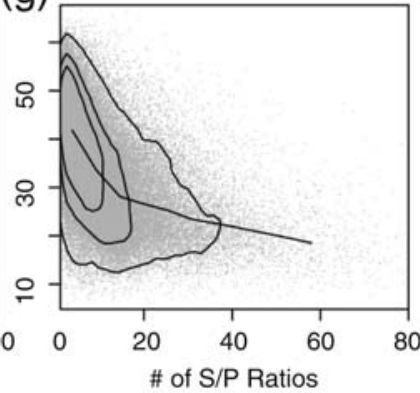

(j)

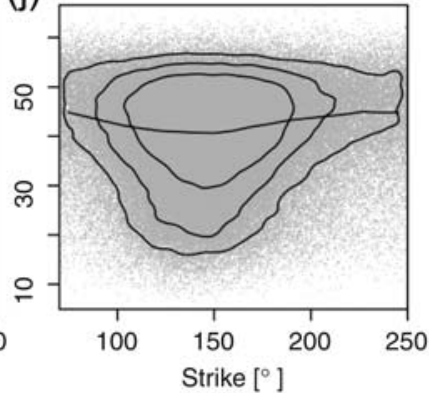

(e)

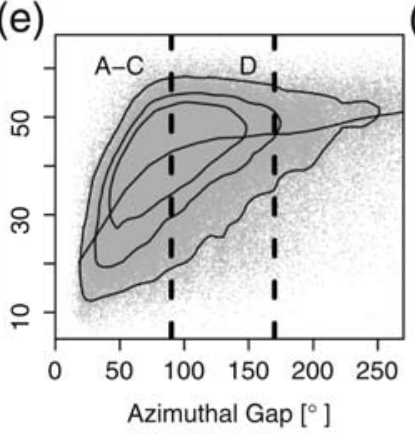

(f)

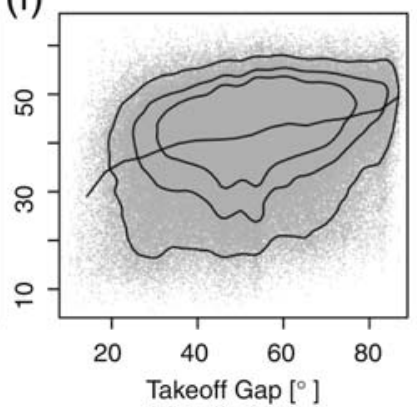

(h)

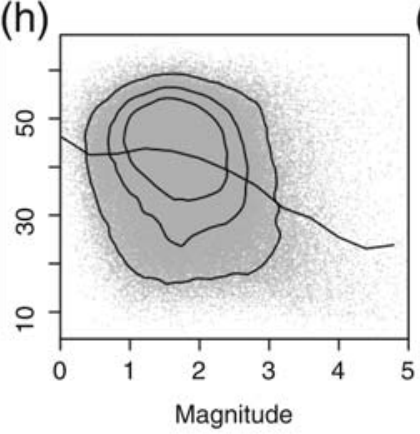

(i)

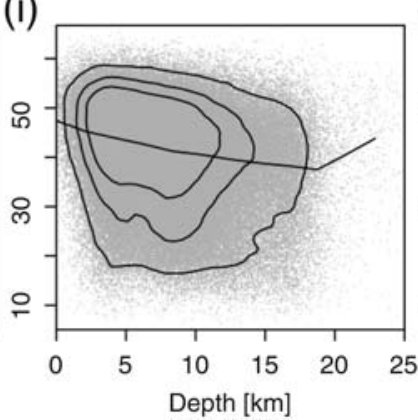

(k)

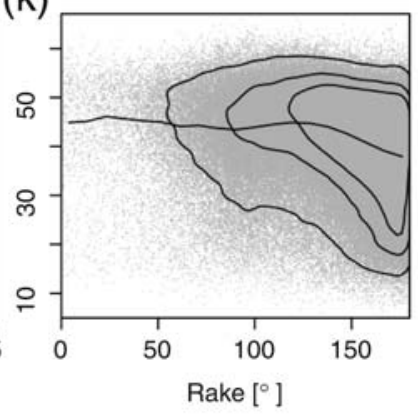

(I)

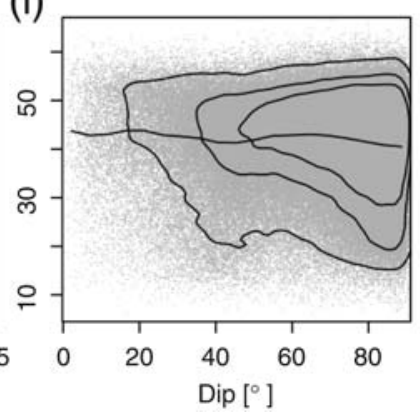

Figure 6. Nodal plane uncertainties (NPU) for $\sim 200,000$ mechanisms with 8 or more first motions plotted versus: (a) mechanism probability, (b) STDR, (c) polarity misfit, (d) number of polarities, (e) azimuthal gap, (f) takeoff gap, (g) number of $S / P$ ratios, (h) magnitude, (i) depth, (j) strike, (k) rake, and (l) dip. In each panel, the three contour lines represent the $90 \%, 70 \%$, and $50 \%$ data kernel density distribution (Venables and Ripley, 2002) from outer to inner contour as illustrated in (b). The black line represents the median nodal plane uncertainties in 20 bins along the range of the x-axis with at least 100 samples in each bin. The four dashed lines in (a) mark the mean nodal plane uncertainty boundaries in the definition of qualities, and the two dashed lines in (e) mark the azimuthal gap boundaries in the definition of qualities.

of the nodal plane uncertainties. When the earthquake occurs at the edge of the network, even though the data from many stations might give a small mean nodal plane uncertainty, the quality of the focal mechanism could be systematically biased because most of the stations were concentrated in one quadrant of the focal sphere. Therefore, we classified the qualities of focal mechanisms based on two parameters: the mean nodal plane uncertainty and the azimuthal gap. We used a $90^{\circ}$ azimuthal gap to select quality A-C focal mechanisms with the observation that the nodal plane uncertainty decreases rapidly when the azimuthal gap is below $90^{\circ}$ (Fig. 6e). Because the mechanism probability could still be 1.0 when the mean nodal plane uncertainty is below $25^{\circ}$ (Fig. 6a), we defined those focal mechanisms with a mean nodal plane uncertainty equal to or less than $25^{\circ}$ as quality A. Because the mean nodal plane uncertainty itself is a measurement of quality, we linearly defined quality B to $\mathrm{C}$ in every $10^{\circ}$ interval from $25^{\circ}$ to $45^{\circ}$. We relaxed the requirement for quality $\mathrm{D}$ for the purpose of including more events without losing much accuracy. We used the $70 \%$ contour line in Figure 6e to define the azimuthal gap of quality D to be up to $170^{\circ}$ and the mean nodal plane uncertainty of quality $\mathrm{D}$ to be up to $55^{\circ}$ for the rest of the events besides quality A-C. In Table 1, we listed the selection criteria and associated numbers of focal mechanisms for different qualities. The set of selection criteria we chose is one of the many possible criteria sets that can be used to define alphabetic qualities. Generally, the population of different quality increases alphabetically for a reasonably defined criteria set. By applying this set of filtering criteria, we obtained a high-quality focal-mechanism catalog with approximately 179,000 earthquakes. As quality decreases from A to D, the 


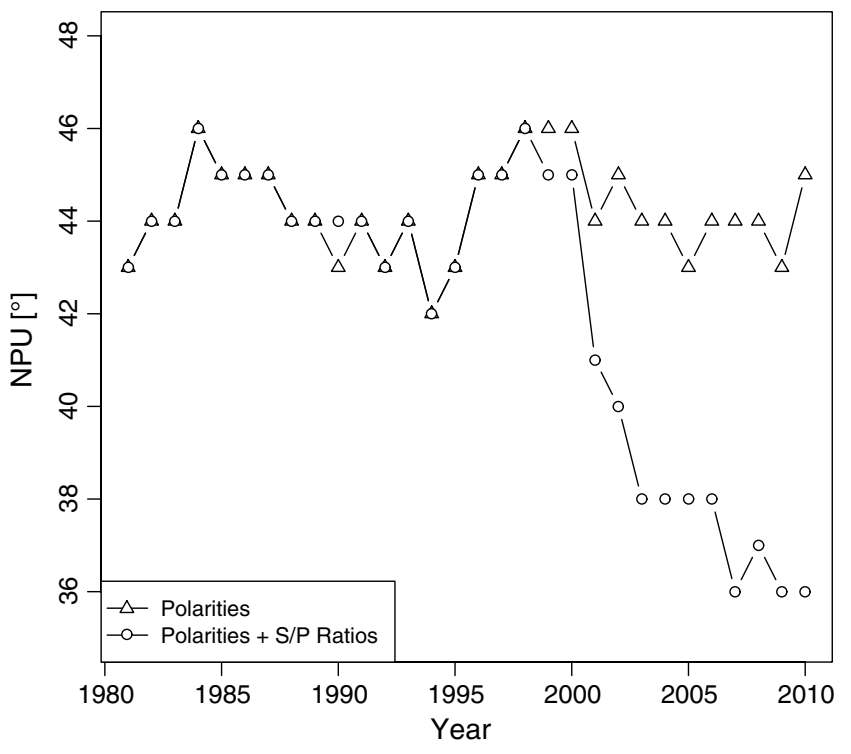

Figure 7. The temporal variation of median annual nodal plane uncertainties (NPU) of focal mechanisms obtained by using polarities only (curve with triangles) and using both polarities and $S / P$ ratios (curve with circles).

geographical coverage of data extends further to the edges of the SCSN coverage region. (E)Figure S2 (see the electronic supplement) shows the geographical distribution of focal mechanisms with different qualities.

\section{Regional Style of Faulting}

To analyze the style of faulting, we classified earthquakes with focal mechanisms as normal, reverse, and strikeslip faulting based on rake angle with a simple $90^{\circ}$ separation rule: events with rake angles from $-45^{\circ}$ to $-135^{\circ}$ exhibit normal faulting, events from $45^{\circ}$ to $-135^{\circ}$ exhibit reverse faulting, and the remaining events exhibit strike-slip faulting with any rake angles. The average style of faulting is summarized by magnitude thresholds in Table 2 . In all magnitude thresholds, the strike-slip faulting events constitute more than $2 / 3$ of all mechanisms. With magnitude threshold ranging from 0.0 to 5.0, the fraction of reverse faulting increases from $11 \%$ to $21 \%$, and the fraction of normal faulting drops from $22 \%$ to $3 \%$. Such a change in style of faulting with increasing magnitude threshold is consistent with the fact that the large earthquakes that occurred in the recent past in southern

Table 1

Definition of Focal-Mechanism Qualities

\begin{tabular}{cccc}
\hline Quality & $\begin{array}{c}\text { Mean Nodal Plane } \\
\text { Uncertainty }\end{array}$ & $\begin{array}{c}\text { Azimuthal } \\
\text { Gap }\end{array}$ & $\begin{array}{c}\text { Number of } \\
\text { Mechanisms }\end{array}$ \\
\hline A & $\leq 25^{\circ}$ & $\leq 90^{\circ}$ & 12,994 \\
B & $25^{\circ}-35^{\circ}$ & $\leq 90^{\circ}$ & 24,359 \\
C & $35^{\circ}-45^{\circ}$ & $\leq 90^{\circ}$ & 40,237 \\
D & Others, with $\leq 55^{\circ}$ & $\leq 170^{\circ}$ & 101,309 \\
Total & & & 178,899 \\
\end{tabular}

Table 2

Focal Mechanisms by Style of Faulting with Different Magnitude Thresholds

\begin{tabular}{crccc}
\hline $\begin{array}{c}\text { Magnitude } \\
\text { Threshold }(M \geq)\end{array}$ & $\begin{array}{c}\text { Total } \\
\text { Number }\end{array}$ & $\begin{array}{c}\text { Strike-Slip } \\
(\%)\end{array}$ & $\begin{array}{c}\text { Reverse } \\
(\%)\end{array}$ & $\begin{array}{c}\text { Normal } \\
(\%)\end{array}$ \\
\hline 0.0 & 178,891 & 67 & 11 & 22 \\
1.0 & 163,155 & 67 & 11 & 22 \\
2.0 & 59,721 & 72 & 11 & 17 \\
3.0 & 6935 & 75 & 13 & 12 \\
4.0 & 745 & 77 & 16 & 7 \\
5.0 & 73 & 76 & 21 & 3 \\
\hline
\end{tabular}

California are either strike-slip or reverse faulting earthquakes.

To determine the earthquake statistics as a function of the mechanism type, the cumulative frequency and magnitude relationships for the three faulting styles and all events are shown in Figure 8a. We calculated the $b$-values for each style with magnitudes above 2.5 using the maximum likelihood method (Aki, 1965) and estimated associated errors using the method in Shi and Bolt (1982). The $b$-value is $0.994 \pm 0.007$ for all faulting styles, $0.983 \pm 0.008$ for strike-slip faulting, $0.900 \pm 0.018$ for reverse faulting, and $1.165 \pm 0.021$ for normal faulting.

To determine the variation in focal mechanisms with depth, we plotted the three faulting styles as probability density functions with depth in the $0-20-\mathrm{km}$ range as shown in Figure $8 \mathrm{~b}$. All styles share common depth probability densities with a maximum at around the 8-km depth. At around the 4-km depth, strike-slip faulting and normal faulting have a second maximum. For depths shallower than $\sim 8 \mathrm{~km}$, the probability densities of strike-slip and normal faulting are higher than for reverse faulting, while the opposite holds for depths beneath $8 \mathrm{~km}$. Such a pattern of mechanism styles with depth is different from what was found for the east Los Angeles area by Yang and Hauksson (2011). This is in part because the east Los Angeles area has clear vertical differential movement controlled by tectonic compression and escape tectonics between the Transverse Range and the Peninsular Range, while the southern California region as a whole is dominated by the horizontal right-lateral strikeslip plate boundary motion.

We use the distributions of the $P$ and $T$ axes to illustrate the dominant deformation field in southern California. By definition, focal mechanisms of reverse faulting have nearvertical $T$ axes and focal mechanisms of normal faulting have near-vertical $P$ axes. To analyze the population of focal mechanisms, we determined the statistical distributions of $P$ and $T$ axes for focal mechanisms of different faulting styles in Figure $8 \mathrm{c}-\mathrm{f}$. The probability density distributions of the azimuths of the $P$ axes for the three styles of faulting are shown in Figure 8c. Because the $P$-axis azimuths for all three faulting styles follow a $180^{\circ}$ circular systematic distribution, we combined the $P$-axis azimuths into a $\pm 90^{\circ}$ azimuth range relative to the north with positive to the east. The peak value 
(a)

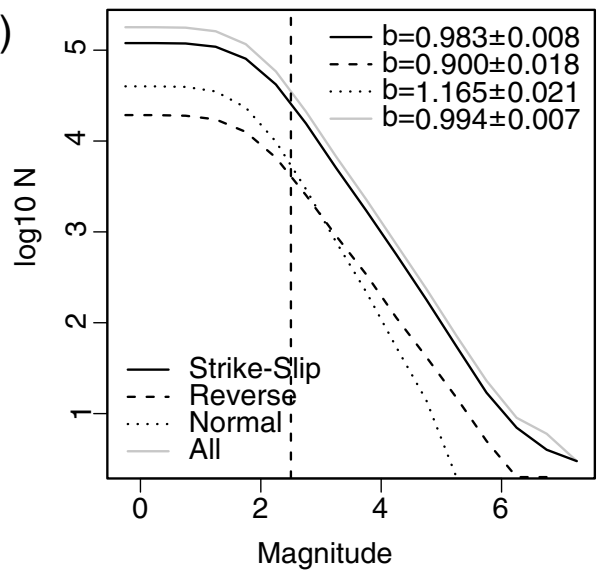

(c)

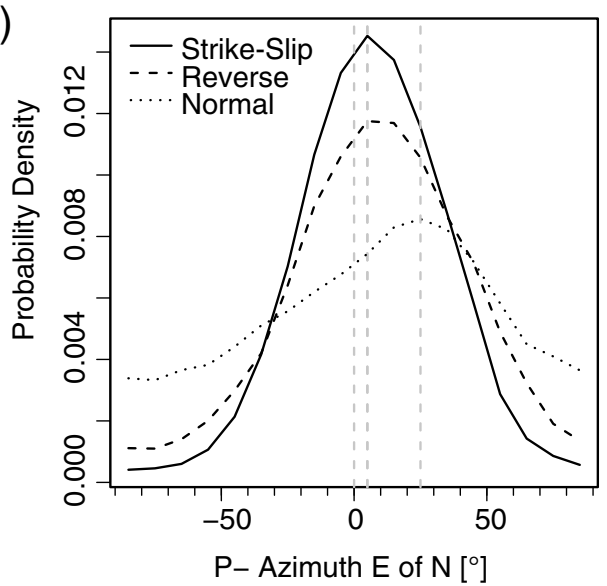

(e)

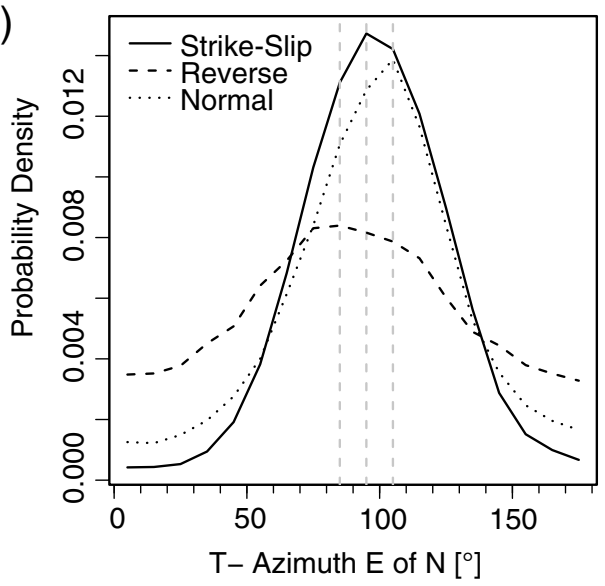

(b)

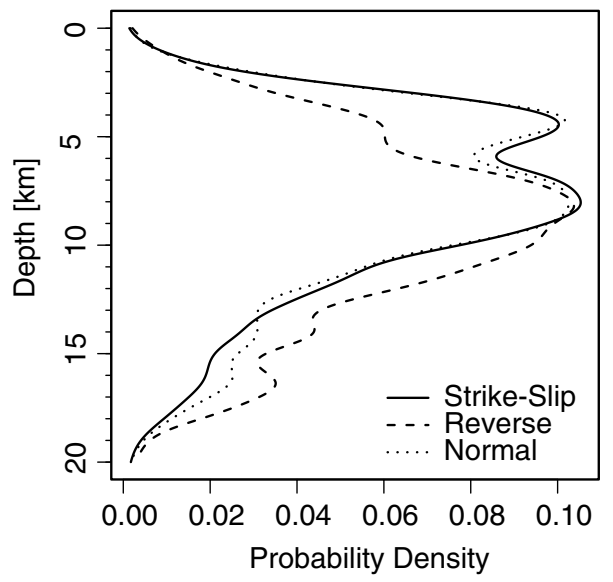

(d)

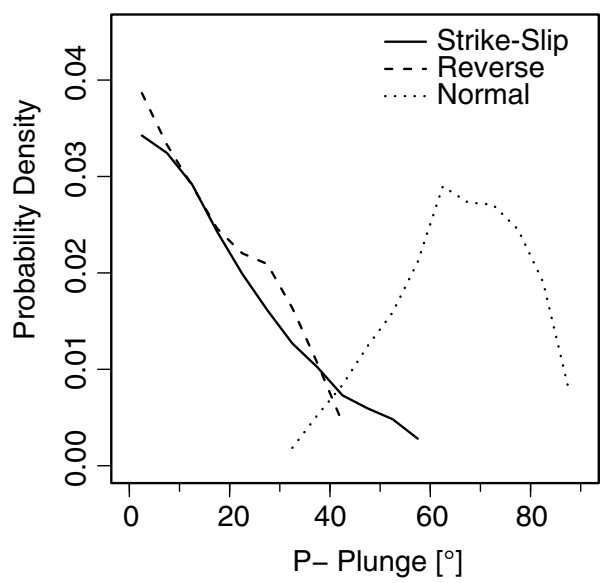

(f)

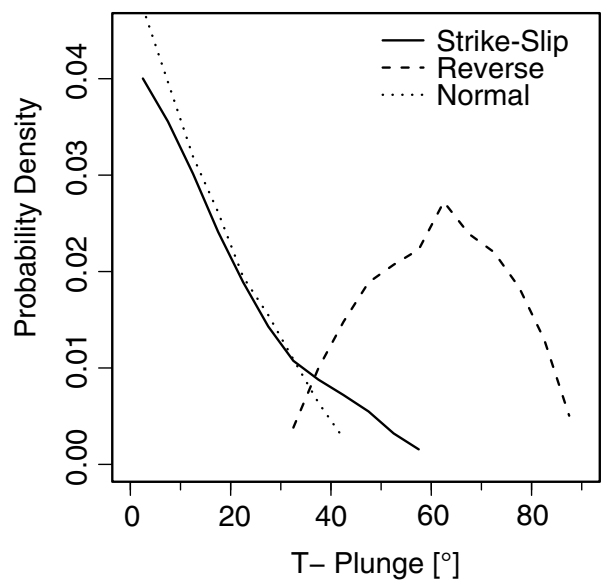

Figure 8. (a) Magnitude frequency relationships for earthquakes of different styles of faulting in the refined focal-mechanism catalog. The vertical dashed line marks the magnitude cutoff for the $b$-value calculation. The legend is shown at the bottom left corner, and the associated $b$-values are labeled at the top right corner. (b) The probability density distributions of three faulting styles as a function of depth from 0 to $20 \mathrm{~km}$. (c) The probability density distributions of azimuths of the $P$ axes for the three faulting styles. The peak of each distribution is marked by a gray dashed line. (d) The probability density distributions of the plunges of the $P$ axes for the three faulting styles. (e) The probability density distributions of azimuths of the $T$ axes for the three faulting styles. The peak of each distribution is marked by a gray dashed line. (f) The probability density distributions of the plunges of the $T$ axes for the three faulting styles.

of the $P$-axis azimuth distribution is $5^{\circ}, 15^{\circ}$, and $25^{\circ}$ for the strike-slip, reverse, and normal faulting, respectively. The variance of the $P$-axis azimuth distribution is smallest for the strike-slip style and largest for the normal style.
Figure $8 \mathrm{~d}$ shows the probability density distributions of the plunges of the $P$ axes for the three styles of faulting. The population of $P$-axis plunges for strike-slip and reverse styles peaks at $0^{\circ}$ and decays linearly with the increase of 
plunge up to $60^{\circ}$ and $40^{\circ}$, respectively. The population of $P$-axis plunges for normal faulting is in the range of $30^{\circ}-90^{\circ}$, peaking at $60^{\circ}$.

In comparison, the probability density distributions of the azimuths of $T$ axes for the three styles of faulting are shown in Figure 8e. Similar to the $P$-axis azimuths, we combined the $T$-axis azimuths into a $0^{\circ}-180^{\circ}$ azimuth range relative to the north with positive to the east. The peak value of the $T$-axis azimuth distribution is $95^{\circ}, 85^{\circ}$, and $105^{\circ}$ for strike-slip, reverse, and normal faulting, respectively. The variance of the $T$-axis azimuth distribution is smallest for the strike-slip style and largest for reverse faulting. Figure $8 \mathrm{f}$ shows the probability density distributions of the plunges of the $T$ axes for the three styles of faulting. The population of the $T$-axis plunges for strike-slip and normal faulting peaks at $0^{\circ}$ and decays linearly with the increase of plunges up to $60^{\circ}$ and $40^{\circ}$, respectively. The population of the $P$-axis plunges for reverse faulting varies in the range of $30^{\circ}-90^{\circ}$, with a peak at $60^{\circ}$.

The $P$ - and $T$-axis distributions thus are consistent with the overall strike-slip tectonics of southern California. In limited areas of dip-slip faulting, the $P$ or $T$ axes are more steeply dipping, reflecting crustal thinning or thickening.

We have plotted the geographic distribution of focal mechanisms of quality A for southern California in Figure 1. To further visualize the distribution of focal mechanisms of different faulting styles at a smaller scale, we subdivided southern California into six regions as illustrated in (E)Figure S4 (see the electronic supplement) and plotted focal mechanisms of qualities A-C in each region in Figures S5-S10, respectively (see the electronic supplement).

\section{Temporal Variations in Style of Faulting}

We analyzed the temporal variations in $P / T$-axis azimuths and plunges of the four quality groups of focal mechanisms over the last 30 years (Fig. 9). Generally, the distribution of $P / T$-axis azimuths and plunges are stable with no obvious temporal dependency except for some perturbations with short periods due to the occurrences of major regional earthquakes. The shape of the probability density distribution for each parameter becomes more and more centralized as

(a)

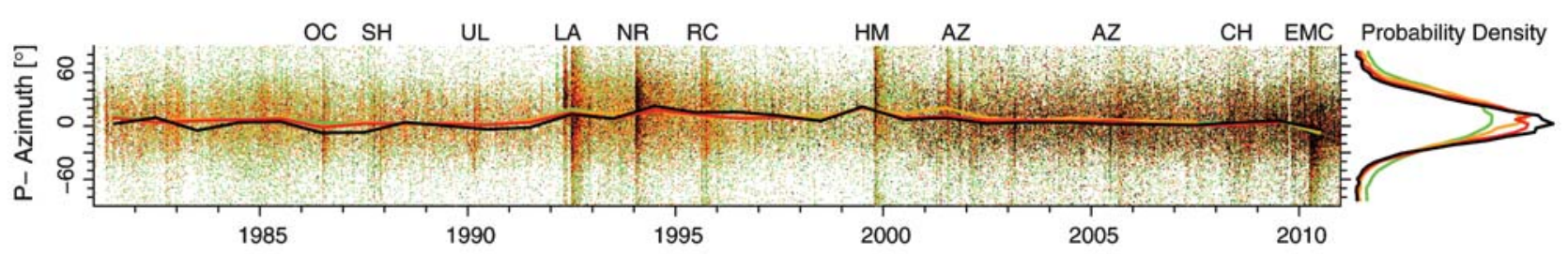

(b)

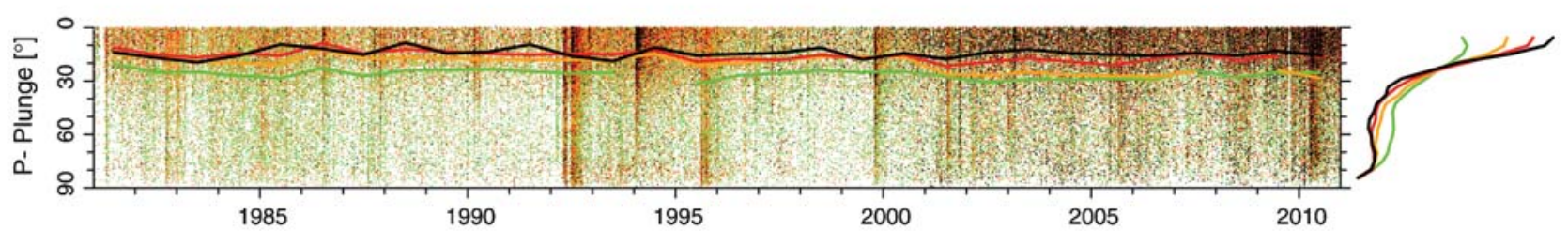

(c)

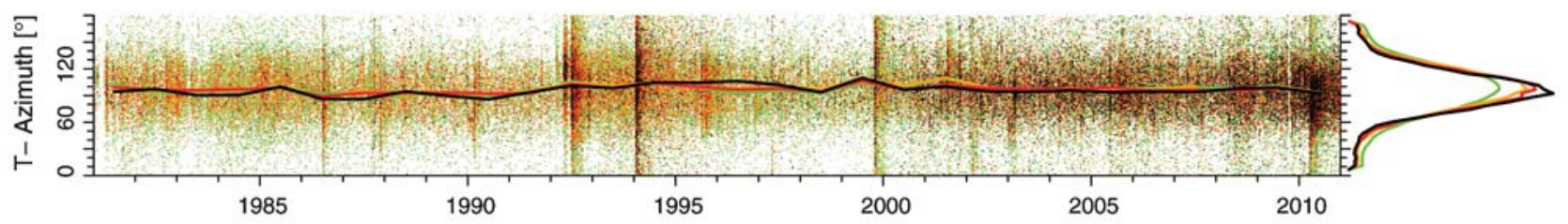

(d)

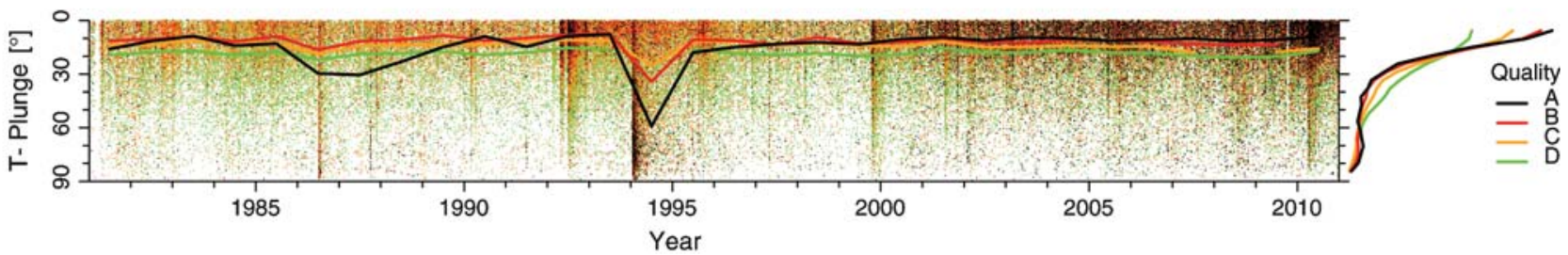

Figure 9. (a) The temporal variations of $P$-axis azimuths, (b) the $P$-axis plunges, (c) the $T$-axis azimuths, and (d) the $T$-axis plunges for quality A (black), B (red), C (yellow), and D (green) data in the refined focal-mechanism catalog. In each subplot, the four curves plotted to the right represent the annual median value for different qualities and the probability density distribution of each parameter over time for the four qualities. The color legend is shown in the bottom right corner. In (a), significant earthquakes in southern California are marked chronologically with OC (1986 Oceanside $M_{\mathrm{L}}$ 5.4), SH (1987 Superstition Hills $M_{\mathrm{w}} 6.6$ ), UL (1988 Upland $\left.M_{\mathrm{L}} 4.7\right)$, LA (1992 Landers $M_{\mathrm{w}}$ 7.3), NR (1994 Northridge $M_{\mathrm{w}}$ 6.7), RC (1995 Ridgecrest $M_{\mathrm{L}}$ 5.4), HM (1999 Hector Mine $M_{\mathrm{w}}$ 7.1), AZ (2001 Anza $M_{\mathrm{L}} 5.1$ ), AZ (2005 Anza $M_{\mathrm{w}}$ 5.2), CH (2008 Chino Hill $M_{\mathrm{w}}$ 5.4), and EMC (2010 El Mayor-Cucapah $M_{\mathrm{w}}$ 7.2) on the top. 
focal-mechanism quality improves. The $P / T$-axis azimuth distributions for all qualities follow the Gaussian distribution, with the most likely value centering in the north and east direction, respectively. The $P$ - and $T$-axis plunge distributions peak at $0^{\circ}$ and decay as the plunges increase. The median values of the annual $P / T$-axis plunges are relatively large for the quality D population compared to the populations of other qualities, and it is due to less data constraints.

Right after the occurrence of moderate to large earthquakes in the southern California region, a short period of focal parameter perturbation generally exists, with the mean value close to that for the mainshock. Over the three decades, the occurrence of the Northridge earthquake sequence $\left(M_{\mathrm{w}} 6.7,1994\right)$ caused a perturbation to the background focal parameters, especially to the plunges of $T$ axes (Fig. 9d), with the triggering of many low angle dip-slip aftershocks. In comparison, the occurrence of the larger magnitude earthquakes such as the $1992 M_{\mathrm{w}} 7.3$ Landers, the $1999 M_{\mathrm{w}} 7.1$ Hector Mine, and the recent $2010 M_{\mathrm{w}} 7.2$ El MayorCucapah earthquakes had little effect on the background style of faulting. From Figure 9 we also can see that the relative number of quality A and B events had increased since 2000 because of the SCSN upgrade.

Although the $P$ and $T$ axes obtained for a single earthquake can not be used to represent the orientations of maximum and minimum stresses (McKenzie, 1969), the mean directions of $P$ and $T$ axes over a large number of earthquakes are consistent with the orientations of maximum and minimum stresses regionally (e.g., Hardebeck and Hauksson, 2001). Therefore, the temporal evolution of the regional stress field in southern California could be investigated by the study of the temporal changes of $P$ - and $T$-axis distributions. As shown in the Figure 9, the annual distribution of $P$ and $T$ axes is generally in the north-south, and the east-west direction, respectively.

To further investigate the azimuth variations of $P$ and $T$ axes at a fine scale, we plotted the normalized annual $P$ - and $T$-axis azimuth distributions within the range of $-50^{\circ}$ to $50^{\circ}$ to the north and east over time in Figure 10a and b, respectively. The mean values (dots) and peaks (brightest bars) of the annual $P$ - and $T$-axis distributions vary generally in the range of $0^{\circ}-20^{\circ}$ to the east of north and to the south of east respectively, except in 1986 and 2010, where the mean and peak values of $P$-axis distributions were in the range of $10^{\circ}$ to the west of north. Following the 1992 Lander earthquake, the annual $P$-axis azimuth distributions rotated more to the east, reached the maximum mean value at $20^{\circ}$ in 1999 , and returned to the pre-Lander pattern in 2002. During the same 10 -year period, the annual $T$-axis azimuth distributions had also rotated more to the south of east.

\section{Discussion}

The southern California region is dominated by strike-slip faulting with the most dominant $P$ and $T$ axes in north-south and east-west directions, respectively. This style of faulting is associated with the relative motion along
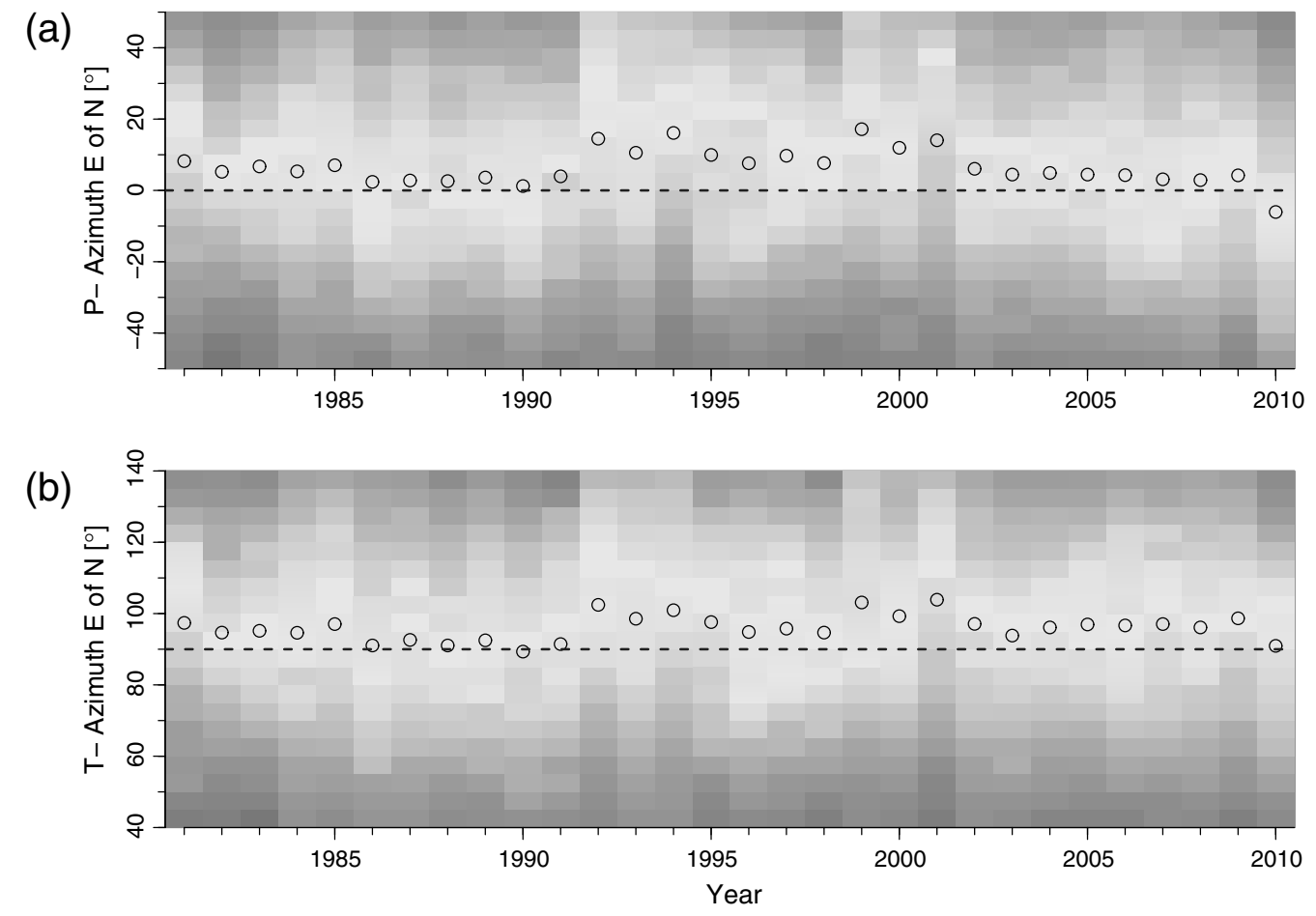

Figure 10. Temporal variations of (a) the normalized annual $P$-axis azimuth distributions and (b) the normalized annual $T$-axis azimuth distributions in the range of $\pm 50^{\circ}$ to the northeast direction, respectively. The dashed lines in (a) and (b) mark the northeast direction. For each normalized annual distribution, the mean is marked by an open dot, and the peak density is marked by the brightest bar. 
the Pacific-North America plate boundary ( Fig. 1, inset panel) and matches the Global Positioning System (GPS) observation of the current crustal deformation velocity field in the southern California region (e.g., Meade and Hager, 2005). However, the spatial distribution of faulting styles is not homogeneous and varies geographically across southern California (Fig. 1) with most earthquakes exhibiting reverse faulting in the Transverse Ranges, a combination of all three faulting styles in the San Bernardino mountains, and mostly strike-slip faulting elsewhere. In general, normal faulting earthquakes coincide in location with strike-slip faulting earthquakes, and both faulting styles share the same depth distribution (Fig. 8b).

From the analysis of around 22,000 focal mechanisms with magnitudes above 2.5 in this catalog, we obtained a relationship between $b$-value and the styles of faulting. The $b$ value decreases with the styles of faulting following the order from normal faulting, to strike-slip faulting, to reverse faulting, which is consistent with the findings of previous studies (e.g., Hauksson 1990; Schorlemmer et al., 2005; Yang and Hauksson, 2011). Earthquakes with reverse faulting occurred at relatively deeper depth compared to earthquakes of the other two faulting styles (Fig. 8b), and geographically earthquakes with reverse faulting have greater depth extent in seismogenic zones than earthquakes for other faulting styles (Hauksson, 2011).

In addition to the $b$-values, the distributions of $P$ and $T$ axes for earthquakes of different faulting styles also exhibit some systematic variations (Fig. 8c and e). The most likely $P$-axis azimuth for strike-slip faulting earthquakes is $\mathrm{N} 5^{\circ} \mathrm{E}$, $\mathrm{N} 10^{\circ} \mathrm{E}$ for reverse faulting earthquakes, and $\mathrm{N} 25^{\circ} \mathrm{E}$ for normal faulting earthquakes. The most likely $T$-axis azimuth for strike-slip faulting is $\mathrm{E} 5^{\circ} \mathrm{S}, \mathrm{E} 5^{\circ} \mathrm{N}$ for reverse faulting, and $\mathrm{E} 15^{\circ} \mathrm{S}$ for normal faulting earthquakes. By definition, the angle between $P$ and $T$ axes azimuths is $90^{\circ}$, and it matches well with the $P$ - and $T$-axis azimuth distributions for strike-slip faulting because both axes are in the horizontal domain. For the normal and reverse faulting styles, because one of the $P$ and $T$ axes is almost vertical, the associated azimuth distribution has large variance, and the most likely value has large uncertainty.

Over the last 30 years, the statistical distribution of $P$ and $T$ axes for earthquake focal mechanisms in southern California has remained stable, with no significant temporal variation except for some short periods of perturbations immediately after the occurrences of major earthquakes (Fig. 9). Hardebeck and Hauksson (2001) also showed that there was no temporal change of the regional stress field in southern California from 1981 to 1999 . The temporal stability of the style of faulting suggests that a 30-year period is representative of the long-term plate tectonic loading process. In general, the mean of the annual $P$ and $T$ axes varied in the range of $0^{\circ}-10^{\circ}$ to the east of north and to the south of east, respectively, before the $1992 M_{\mathrm{w}} 7.3$ Lander earthquake. In the 10year period (1992-2002) since the occurrence of the Landers earthquake, both axes had rotated more clockwise, or about $10^{\circ}$ (Fig. 10a and b). During the same time period, the East California Shear Zone and the Transverse Ranges were relatively active with the occurrences of the 1992 Lander earthquake, the 1994 Northridge earthquake, and the 1999 Hector Mine earthquake. All of these mainshocks triggered large aftershock sequences, and the orientations of the maximum horizontal stresses in both areas were in the direction $\mathrm{N} 20^{\circ} \mathrm{E}-$ $\mathrm{N} 35^{\circ} \mathrm{E}$, while the orientations of the maximum horizontal stresses in other parts of southern California were approximately in the north-south direction (Hardebeck and Hauksson, 2001). Therefore, the approximately $10^{\circ}$ clockwise rotation of the regional $P$ and $T$ axes during the 1992-2002 period was associated with the large earthquake sequences in the East California Shear Zone and the Transverse Ranges. Following the occurrence of the El Mayor-Cucapah earthquake in 2010, numerous earthquakes were triggered along major faults in the Peninsular Ranges (Hauksson et al., 2010). The $P$-axis azimuth distributions in 2010 rotated to the west of north, but the only time previously that such rotation was observed was in 1986.

To provide an independent evaluation of the quality of the new focal mechanisms, we compared our catalog with other focal-mechanism catalogs for southern California. Using the HASH program, Hardebeck and Shearer (2003) calculated 24,338 focal mechanisms for events that occurred in the southern California region from 1984 to 2003. We compared the distribution of focal-mechanism parameters (strike, dip, and rake) for 23,420 common events in their catalog (here referred as HS2003) and in our high-quality catalog (here referred as YHS2010). Generally the distributions of focal-mechanism parameters for common events in both catalogs match very well, and both catalogs share similar statistical features. Because the YHS2010 catalog includes records from 1981 to 2010, it supersedes the HS2003 catalog. (E)Figure S3 (see the electronic supplement) shows the comparison of the distributions of focal-mechanism parameters (strike, dip, and rake) for common events in both catalogs.

By fitting observed and synthetic waveforms, Tape et al. (2010) inverted for moment tensors for a data set with 234 earthquakes that occurred in the southern California region in the period of 1998-2009 with magnitudes between 3.5 and 5.5 (hereafter referred to as Tape2010). Using these focal mechanisms as benchmarks, we compared the rotation angles of 210 common events in both catalogs. About $70 \%$ of the common events have rotation angles that are less than $35^{\circ}$, which is the uncertainty value we used to define quality $\mathrm{B}$ focal mechanism (Fig. 11, top right inset panel) and a typical nodal plane uncertainty in the total polarity and $S / P$ ratio mechanisms. We conclude that two focal mechanisms are the same, within the uncertainty limits, if their relative rotation angle is less than $35^{\circ}$.

The geographical distribution of rotation angles is shown in Figure 11. To visualize the geographical distribution of rotation angles, we subdivided the southern California into grid cells of $20 \times 20 \mathrm{~km}$. For each grid cell with data, we filled it with gray if the median rotation angle of common 
events inside is less than $35^{\circ}$, and otherwise it is shown as solid black. To visualize the difference between focal mechanisms, we plotted the pair of focal plane solutions in both catalogs for one event that has the closest rotation angle to the median value in each grid. The events with larger rotation angles are more common at the edges of the SCSN (such as the northern Baja California, the offshore, and the Sierra Nevada). A few event pairs with relative large rotation angles occur inside the SCSN. The possible reasons could be that there are very few available observations due to the occurrence of an immediate foreshock, large azimuthal gap, or a very complicated source process.

We also compared the distributions of dip angles in both catalogs for the 210 common earthquakes (Fig. 11, top left inset panel). The Tape2010 catalog has more earthquakes (about $20 \%$ of the total common events) with dip angles in the range of $35^{\circ}-70^{\circ}$ than the YHS2010 catalog. This suggests that the HASH focal-mechanism estimation method, which uses polarities and $S / P$ ratios, may preferentially fit a considerable portion of the oblique-slip earthquakes as high-angle strike-slip earthquakes.

\section{Conclusions}

We have applied the HASH method to compute focal mechanisms using both polarities and $S / P$ ratios for relocated earthquakes that occurred in the southern California region from 1981 to 2010 . The resulting high-quality catalog includes around 179,000 focal mechanisms with qualities from A to D.

This catalog is arguably the best focal-mechanism catalog for southern California because (1) it uses a relocated earthquake catalog with the best possible locations; (2) it uses observations from both polarities and $S / P$ ratios; and (3) it is the most complete and symmetrically obtained focalmechanism catalog for southern California over a 30-year time period and based on an unprecedented quantity and quality of data. With the fitting of both polarities and $S / P$

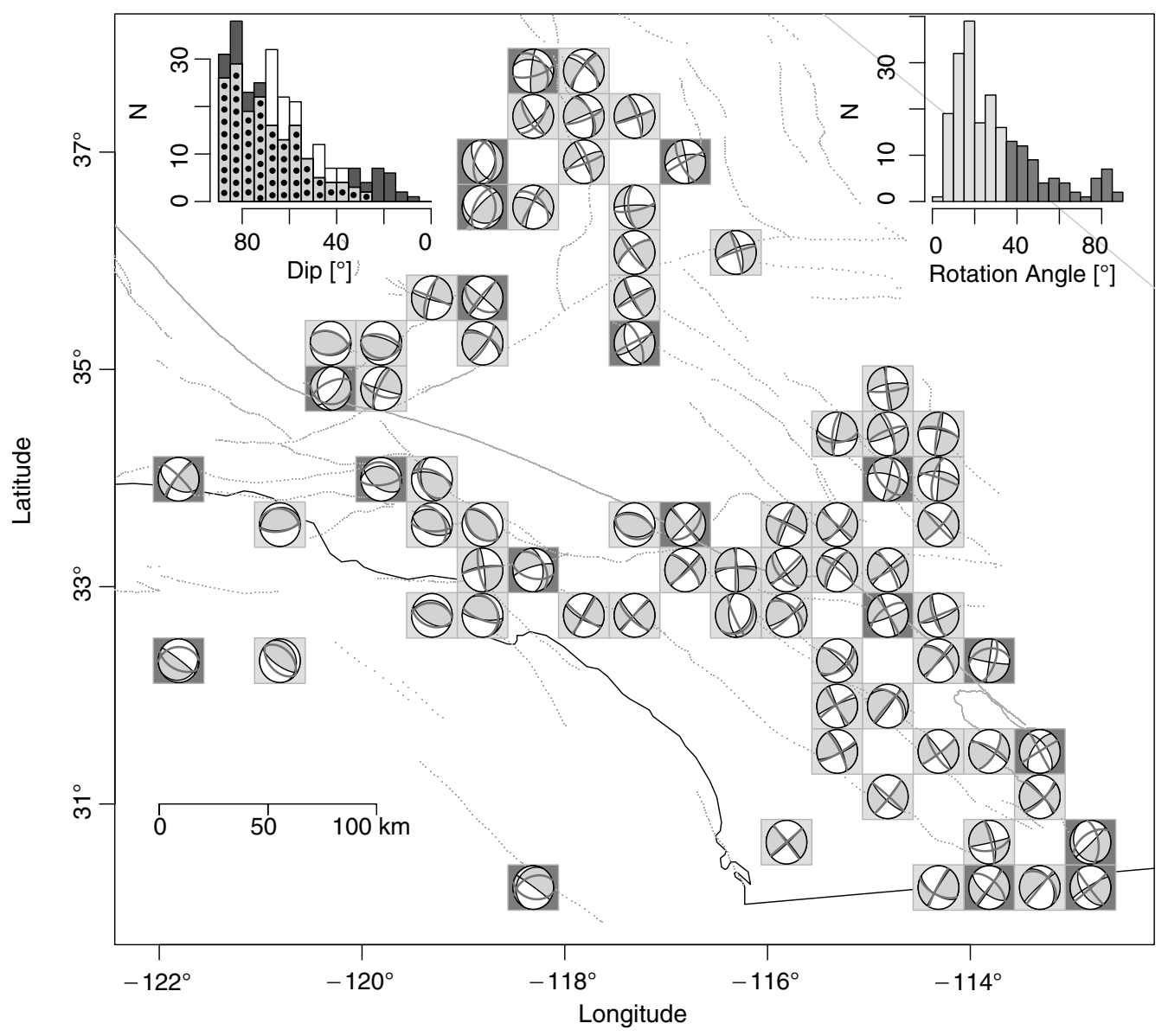

Figure 11. A comparison of 211 focal mechanisms in the YHS2010 catalog with moment-tensor focal mechanisms for the same events determined by Tape et al. (2010). The geographical distribution of gridded median rotation angles shares the same gray scale as is shown in the inset panel in the upper right corner, which shows the histogram of the 211 rotation angles with bars below and above $35^{\circ}$ in gray and black, respectively. At each grid node, we plot a square around the focal-mechanism solutions in YHS2010 (solutions in gray). We also overlay the associated focal planes from Tape et al. (2010) (bold curves) for the events that have the closest rotation angle to the median rotation angle in the grid. The inset panel at the top left corner shows the histograms of common dip angles in YHS2010 (black bars) and in Tape et al. (2010) (white bars), with the overlapped areas in gray with dots. 
ratios, the associated nodal plane uncertainty decreases considerably in comparison to results with only fitting polarities, especially for events that occurred after 2000.

This focal-mechanism catalog generally matches the catalog of Hardebeck and Shearer (2003) but includes many more events over a longer time period. This new catalog makes it possible to investigate the evolution of a contemporary stress field in the southern California region at higher resolution.

Using this new focal-mechanism catalog, we have analyzed the statistical features of faulting styles in the southern California region. The variations of focal parameters have remained temporally stable over the past 30 years. The dominant pattern of faulting is high-angle strike-slip faulting with a small component of normal motion. The $b$-value is largest for normal faulting events and smallest for reverse faulting events. In the low magnitude range (0.0-2.5), there are more normal faulting earthquakes than reverse faulting earthquakes, while the opposite holds for events with magnitudes above 2.5 .

There are several limitations to this catalog. Because the availability of observations (polarities and $S / P$ ratios) has improved with the growth of the SCSN, there are more high-quality data since 2000 . The data quality has also been improved by denser station coverage. Within the coverage area of the SCSN, the focal mechanisms are of high quality, but near or beyond the edges of the SCSN, focal mechanisms can have relatively large uncertainties.

\section{Data and Resources}

The earthquake data used in this study were recorded by the Caltech/USGS SCSN and were made available by the SCEDC. The data were obtained from http://www.data.scec .org (last accessed January 2012), and information about the network was obtained from http://www.scsn.org (last accessed January 2012). The HASH program was downloaded from the USGS (http://earthquake.usgs.gov/research/ software, last accessed January 2012). The focal-mechanism catalog is available for download on the SCEDC webpage (http://www.data.scec.org/research-tools/alt-2011-yanghauksson-shearer.html, last accessed January 2012).

\section{Acknowledgments}

This research was supported by the U.S. Geological Survey Grants G11AP20032 and G12AP20010 and was also supported by the Southern California Earthquake Center (SCEC), which is funded by NSF Cooperative Agreement EAR-0106924 and USGS Cooperative Agreement 07HQAG0008. This article is SCEC contribution number 1512 and contribution number 10066 of the Seismological Laboratory Division of Geological and Planetary Sciences, California Institute of Technology, Pasadena. We are grateful to the operators and analysts who maintain the USGS/Caltech SCSN, and who pick and archive the seismograms. We thank Jeanne Hardebeck for providing the HASH programs and useful discussions. We thank Carl Tape for providing the moment-tensor catalog with 234 earthquakes. We used the RFOC package (Graphics for Spherical Distributions and Earthquake Focal Mechanisms in R) provided by Jonathan Lees to visualize focal mechanisms. We appreciate Sarah Gordon, Shengji Wei, and Zhongwen Zhan for valuable comments. We appreciate associate editor Heather DeShon and two anonymous reviewers for constructive comments.

\section{References}

Aki, K. (1965). Maximum likelihood estimate of $b$ in the formula $\log N=$ $a-b M$ and its confidence limits, Bull. Earthq. Res. Inst. Tokyo Univ. 43, 237-239.

Clinton, J. F., E. Hauksson, and K. Solanki (2006). An evaluation of the SCSN moment tensor solutions: Robustness of the $M_{\mathrm{w}}$ magnitude scale, style of faulting, and automation of the method, Bull. Seismol. Soc. Am. 96, 1689-1705, doi 10.1785/0120050241.

Hardebeck, J. L., and E. Hauksson (2001). Crustal stress field in southern California and its implications for fault mechanics, J. Geophys. Res. 106, no. B10, 21,859-21,882, doi 10.1029/2001JB000292.

Hardebeck, J. L., and P. M. Shearer (2002). A new method for determining first-motion focal mechanisms, Bull. Seismol. Soc. Am. 92, 22642276, doi 10.1785/0120010200.

Hardebeck, J. L., and P. M. Shearer (2003). Using $S / P$ amplitude ratios to constrain the focal mechanisms of small earthquakes, Bull. Seismol. Soc. Am. 93, 2434-2444, doi 10.1785/0120020236.

Hauksson, E. (1990). Earthquakes, faulting, and stress in the Los Angeles basin, J. Geophys. Res. 95, no. B10, 15,365-15,394, doi 10.1029/ JB095iB10p15365.

Hauksson, E. (2000). Crustal structure and seismicity distribution adjacent to the Pacific and North America plate boundary in southern California, J. Geophys. Res. 105, no. B6, 13875-13903, doi 10.1029/ 2000JB900016.

Hauksson, E., P. Small, K. Hafner, R. Busby, R. Clayton, J. Goltz, T. Heaton, K. Hutton, H. Kanamori, J. Polet, D. Given, L. M. Jones, and D. Wald (2001). : Caltech/USGS element of TriNet 1997-2001, Seismol. Res. Lett. 72, 690-704, doi 10.1785/gssrl.72.6.690.

Hauksson, E., J. Stock, L. K. Hutton, W. Yang, A. Vidal, and H. Kanamori (2010). The $2010 M_{\mathrm{w}} 7.2 \mathrm{El}$ Mayor-Cucapah earthquake sequence, Baja California, Mexico and southernmost California, USA: Active seismotectonics along the Mexican Pacific margin, Pure Appl. Geophys. 168, no. 8-9, 1255-1277, doi 10.1007/s00024-010-0209-7.

Hauksson, E. (2011). Crustal geophysics and seismicity in southern California, Geophys. J. Int. 186, 82-98, doi 10.1111/j.1365246X.2011.05042.x

Hutton, K., J. Woessner, and E. Hauksson (2010). Earthquake monitoring in southern California for seventy-seven years (1932-2008), Bull. Seismol. Soc. Am. 100, 423-446, doi 10.1785/0120090130.

Kagan, Y. Y. (1991). 3-D rotation of double-couple earthquake sources, Geophys. J. Int. 106, 709-716, doi 10.1111/j.1365-246X.1991 .tb06343.x.

Kanamori, H., and D. Anderson (1975). Theoretical basis of some empirical relations in seismology, Bull. Seismol. Soc. Am. 65, 1073-1096.

Kanamori, H., J. Mori, E. Hauksson, T. H. Heaton, L. K. Hutton, and L. M. Jones (1993). Determination of earthquake energy release and ML using TERRAscope, Bull. Seismol. Soc. Am. 83, 330-346.

Kilb, D., and J. L. Hardebeck (2006). Fault parameter constraints using relocated earthquakes: Validation of first motion focal mechanism data, Bull. Seismol. Soc. Am. 96, 1140-1158, doi 10.1785/ 0120040239.

Lee, E., P. Chen, T. H. Jordan, and L. Wang (2011). Rapid full-wave centroid moment tensor (CMT) inversion in a three-dimensional Earth structure model for earthquakes in southern California, Geophys. J. Int. 186, 311-330, doi 10.1111/j.1365-246X.2011.05031.x.

Lin, G., P. Shearer, and E. Hauksson (2007). Applying a three-dimensional velocity model, waveform cross correlation, and cluster analysis to locate southern California seismicity from 1981 to 2005, J. Geophys. Res. 112, no. B12309, 14, doi 10.1029/2007JB004986.

Liu, Q., J. Polet, D. Komatitsch, and J. Tromp (2004). Spectral-element moment tensor inversions for earthquakes in southern California, Bull. Seismol. Soc. Am. 94, 1748-1761, doi 10.1785/012004038. 
Jones, L. M. (1988). Focal mechanisms and the state of stress on the San Andreas fault in southern California, J. Geophys. Res. 93, no. B8, 8869-8891, doi 10.1029/JB093iB08p08869.

Meade, B. J., and B. H. Hager (2005). Block models of crustal motion in southern California constrained by GPS measurements, J. Geophys. Res. 110, B03403, 19, doi 10.1029/2004JB003209.

McKenzie, D. P. (1969). The relation between fault plane solutions for earthquakes and the directions of the principal stresses, Bull. Seismol. Soc. Am. 59, 591-601.

Reasenberg, P., and D. Oppenheimer (1985). FPFIT, FPPLOT and FPPAGE: FORTRAN computer programs for calculating and displaying earthquake fault-plane solutions, U.S. Geol. Surv. Open-File Rept. 85-730 109

Schorlemmer, D., S. Wiemer, and W. Max (2005). Variations in earthquakesize distribution across different stress regimes, Nature 437, 539-542, doi 10.1038/nature04094.

Shearer, P. M. (1997). Improving local earthquake locations using the L1 norm and waveform cross correlation: Application to the Whittier Narrows, California, aftershock sequence, J. Geophys. Res. 102, no. B4, 8269-8283, doi 10.1029/96JB03228.

Shen, Y., D. W. Forsyth, J. Conder, and L. M. Dorman (1997). Investigation of microearthquake activity following an intraplate teleseismic swarm on the west flank of the southern East Pacific Rise, J. Geophys. Res. 102, no. B1, 459-475, doi 10.1029/96JB02852.

Shi, Y., and B. A. Bolt (1982). The standard error of the magnitudefrequency $b$-value, Bull. Seismol. Soc. Am. 72, 1677-1687.

Sue, C., F. Thouvenot, J. Fréchet, and P. Tricart (1999). Widespread extension in the core of the western Alps revealed by earthquake analysis, J. Geophys. Res. 104, no. B11, 25,611-25,622, doi 10.1029/ 1999JB900249.

Tan, Y., and D. V. Helmberger (2007). A new method for determining small earthquake source parameters using short-period $P$ waves, Bull. Seismol. Soc. Am. 97, 1176-1195, doi 10.1785/0120060251.

Tape, C., Q. Liu, A. Maggi, and J. Tromp (2010). Seismic tomography of the southern California crust based on spectral-element and adjoint methods, Geophys. J. Int. 180, 433-462, doi 10.1111/j.1365246X.2009.04429.x.
Venables, W. N., and B. D. Ripley (2002). Modern Applied Statistics with S., Fourth Ed., Springer, New York, 495 pp.

Wang, K., T. Mulder, G. C. Rogers, and R. D. Hyndman (1995). Case for very low coupling stress on the Cascadia subduction fault, J. Geophys. Res. 100, no. B7, 12,907-12,918, doi 10.1029/95JB00516.

Wells, D. L., and K. J. Coppersmith (1994). New empirical relationships among magnitude, rupture length, rupture width, rupture area, and surface displacement, Bull. Seismol. Soc. Am. 84, 974-1002.

Yang, W., and E. Hauksson (2011). Evidence for vertical partitioning of strike-slip and compressional tectonics from seismicity, focal mechanisms, and stress drops in the east Los Angeles basin area, California, Bull. Seismol. Soc. Am. 101, 964-974, doi 10.1785/ 0120100216

Zhao, L. S., and D. V. Helmberger (1994). Source estimation from broadband regional seismograms, Bull. Seismol. Soc. Am. 84, 91-104.

Zhu, L., and D. V. Helmberger (1996). Advancement in source estimation techniques using broadband regional seismograms, Bull. Seismol. Soc. Am. 86, 1634-1641.

Seismological Laboratory

California Institute of Technology

1200 E. California Boulevard

Mail Code 252-21

Pasadena, California 91125

wenzheng@gps.caltech.edu (W.Y., E.H.)

Institute of Geophysics and Planetary Physics

Scripps Institution of Oceanography

University of California at San Diego

La Jolla, California 92093-0225

pshearer@ucsd.edu

(P.M.S.) 